\title{
Fracture mechanics analysis of composite structures using the boundary element shape sensitivities
}

DOI:

10.2514/1.41729

\section{Document Version}

Accepted author manuscript

Link to publication record in Manchester Research Explorer

\section{Citation for published version (APA):}

Tafreshi, A. (2009). Fracture mechanics analysis of composite structures using the boundary element shape sensitivities. AlAA Journal, 47(8), 1926-1938. https://doi.org/10.2514/1.41729

\section{Published in:}

AIAA Journal

\section{Citing this paper}

Please note that where the full-text provided on Manchester Research Explorer is the Author Accepted Manuscript or Proof version this may differ from the final Published version. If citing, it is advised that you check and use the publisher's definitive version.

\section{General rights}

Copyright and moral rights for the publications made accessible in the Research Explorer are retained by the authors and/or other copyright owners and it is a condition of accessing publications that users recognise and abide by the legal requirements associated with these rights.

\section{Takedown policy}

If you believe that this document breaches copyright please refer to the University of Manchester's Takedown Procedures [http://man.ac.uk/04Y6Bo] or contact uml.scholarlycommunications@manchester.ac.uk providing relevant details, so we can investigate your claim.

\section{OPEN ACCESS}




\title{
Fracture Mechanics Analysis of Composite Structures Using the Boundary Element Shape Sensitivities
}

\author{
Azam Tafreshi \\ atafreshi@manchester.ac.uk \\ School of Mechanical, Aerospace and Civil Engineering, University of Manchester, Oxford Road, \\ Manchester, M13 9PL, England, UK
}

Based on the shape sensitivity analysis of multi-region domains using the boundary element method, stress intensity factors of the cracks of arbitrary geometric shapes in anisotropic elastic solids are calculated. The results obtained agree very well with the existing analytical or numerical solutions. In contrast to the J-integral method which would require the computation of stresses and strains at a series of internal points around the crack for evaluation of the path-independent integrals, here the fracture mechanics parameters are evaluated by direct differentiation of the structural response for a multi-region domain. Therefore, the present method is computationally more accurate and efficient. The length of the crack of arbitrary geometric shape is treated as the shape design variable. Then the shape variable is associated with the coordinates of a series of boundary nodes located on the crack surface. Thus, the relevant velocity terms are applied together in the sensitivity analysis with respect to that variable to determine the energy release rate, which is the total derivative of the strain energy with respect to crack length. Five example problems with anisotropic material properties are presented to validate the applications of this formulation. The results show that although the stress intensity factor is of fundamental importance in the prediction of brittle failure using linear elastic fracture mechanics, the direct evaluation of the strain energy release rate would easily characterise the crack instability of a loaded laminated composite for different fibre orientations. The results show that the strain energy release rate is highly influenced by the fibre orientation of the composite lamina. Therefore, a laminate can be tailored to crack growth resistance.

\section{Nomenclature}

$\mathrm{A}_{\mathrm{jk}}=$ complex constants

$\mathrm{a} \quad=$ crack length

$\mathrm{a}_{\mathrm{jk}} \quad=\quad$ elastic compliance matrix $(\mathrm{j}, \mathrm{k}=1,2,6)$

$a_{11}=\frac{1}{E_{1}}, a_{22}=\frac{1}{E_{2}}, a_{12}=-\frac{v_{12}}{E_{1}}=-\frac{v_{21}}{E_{2}}$,

$a_{66}=\frac{1}{G_{12}}, a_{16}=\frac{\eta_{12,1}}{E_{1}}=\frac{\eta_{1,12}}{G_{12}}, a_{26}=\frac{\eta_{12,2}}{E_{2}}=\frac{\eta_{2,12}}{G_{12}}$

$\mathrm{C}=$ ratio of relative displacements

$C_{j k}(P)=$ limiting value of the surface integral of $T_{j k}(P, Q)$ 


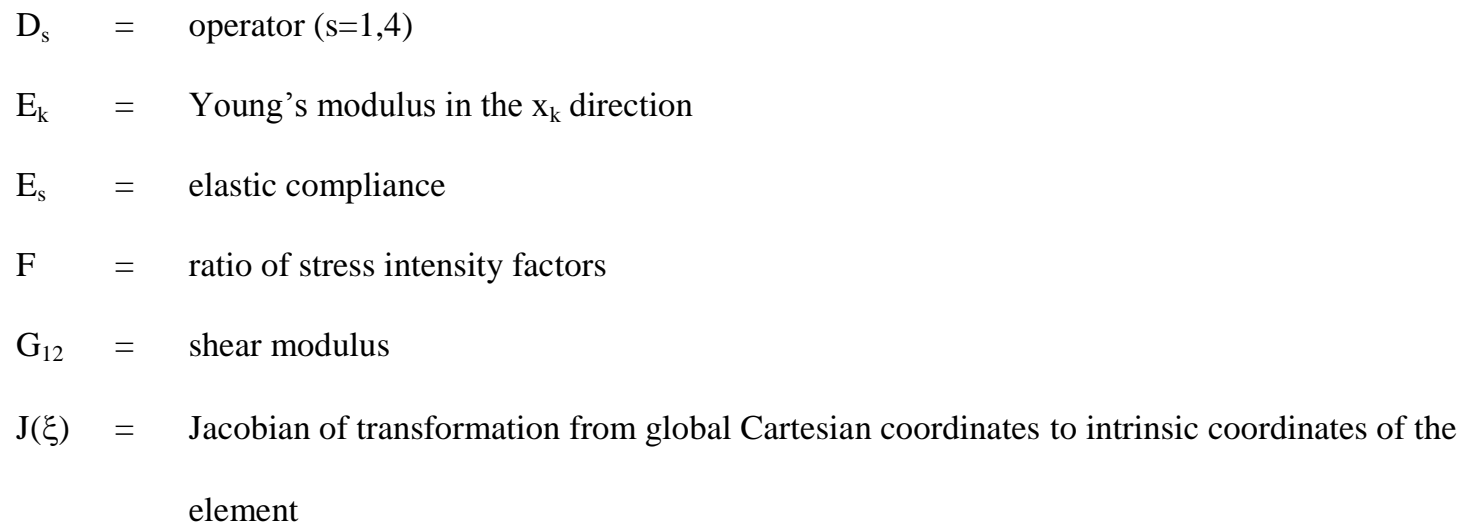

$\mathrm{J}_{\mathrm{k}} \quad=\quad \mathrm{J}$-Integral $(\mathrm{k}=1,2)$

$\mathrm{K}_{\mathrm{I}}, \mathrm{K}_{\mathrm{II}}=\quad$ modes I and II stress intensity factors

$\mathrm{m}_{1 \mathrm{k}}, \mathrm{m}_{2 \mathrm{k}}=$ unit vectors tangent and normal to the surface

$\mathrm{N}^{\mathrm{c}}(\xi)=$ quadratic shape function corresponding to the cth node of the element

$\mathrm{n}_{1}, \mathrm{n}_{2}=$ direction cosines of the unit outward normal vector to the surface of the elastic body

$\mathrm{P}=$ load point at the surface of the elastic domain

$\mathrm{Q}=$ field point at the surface of the elastic domain

$\mathrm{r}_{\mathrm{jk}}=$ complex constants

$\mathrm{s} \quad=\quad$ domain boundary

$\mathrm{s}_{\mathrm{b}}=$ bth-element of the discretized boundary

$\mathrm{s}_{\mathrm{j}} \quad=\quad$ material property parameters

$T_{j k}(P, Q)=j$ th component of the traction vector at point $Q$ due to a unit point load in the kth direction at $\mathrm{P}$

$\mathrm{t}_{\mathrm{j}}=$ traction vector

$\mathrm{U}_{\mathrm{jk}}=\mathrm{jth}$ component of the displacement vector at point $\mathrm{Q}$ due to a unit point load in the kth direction at $\mathrm{P}$

$\mathrm{u}_{\mathrm{j}} \quad=\quad$ displacement vector

$\mathrm{W}=$ strain energy density

$\mathrm{x}_{\mathrm{i}}=$ rectangular Cartesian coordinates

$\overline{\mathrm{X}}_{1}, \overline{\mathrm{x}}_{2}=$ local coordinates on an element

$\mathrm{z}_{\mathrm{j}} \quad=\quad$ complex coordinates

$\alpha_{\mathrm{j}}, \beta_{\mathrm{j}}=$ real constants

$\delta_{\mathrm{jk}}=$ Kronecker delta 


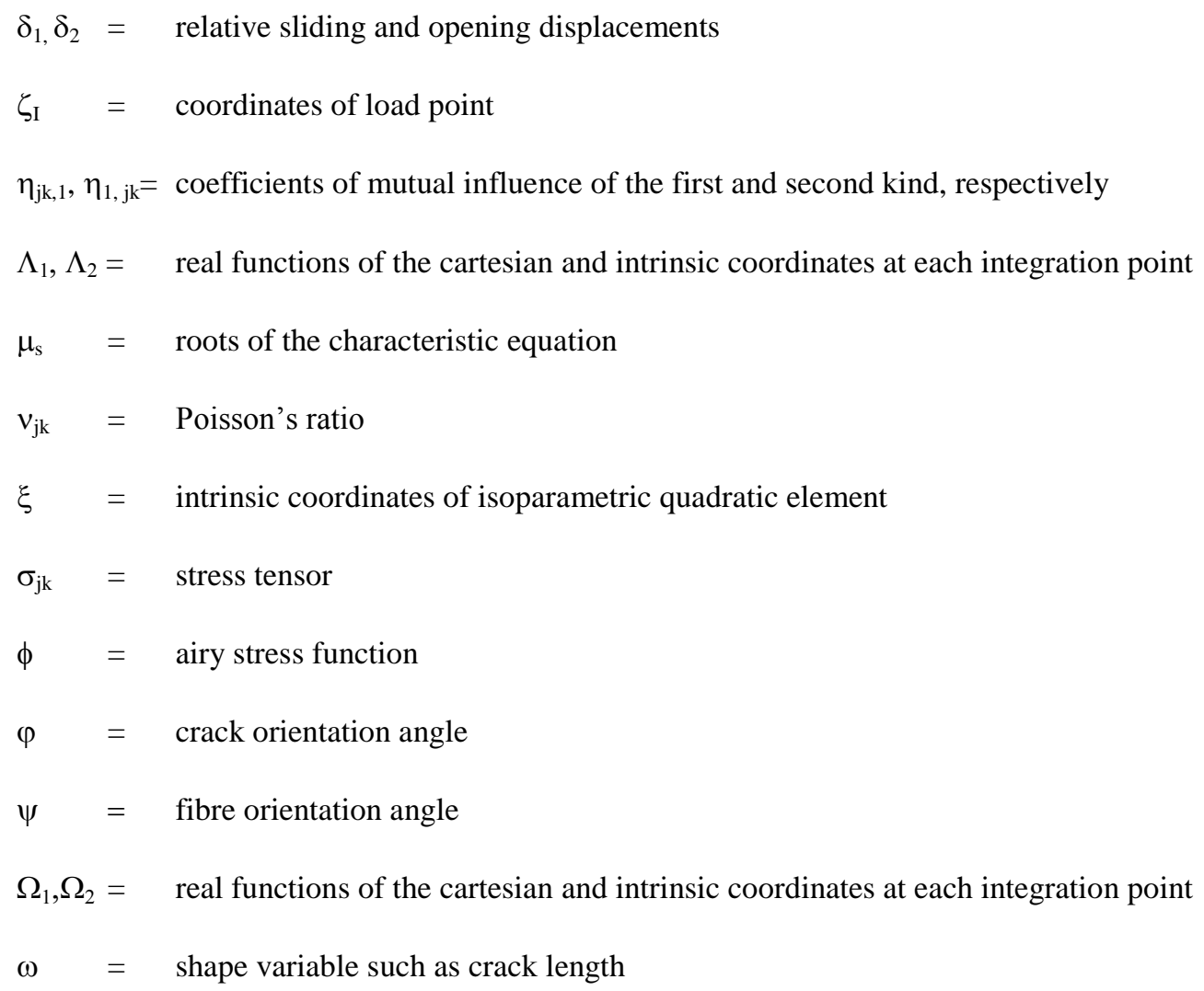

\section{Introduction}

The application of composites in aerospace, automobile, civil and marine industries is well established today due to the known benefits such as high specific stiffness or strength and the material's tailoring facilities for creating high performance structures. With the increasing need to produce lighter weight aerospace structures, the use of advanced composite materials has become more common in the design of these structures. Military and civilian aircraft structures are prone to cracking due to wear and tear, especially when they are used beyond their fatigue life. Cracked structures on an aircraft could lead to a catastrophic failure because the tensile strengths of composite laminates are significantly reduced when stress concentrations such as cracks and cutouts are present. Solutions to these problems in anisotropic elasticity are therefore of great interest in the design and strength analysis of composite structures [1-11]. The Finite Element(FE) and Boundary Element(BE) are the most extensively used methods for the analysis of engineering structures. The latter seems to have proved advantageous for solving fracture mechanics problems. Early contribution to the development of the Boundary Element Method (BEM) for cracked anisotropic plates belongs to Synder and Cruse[1].

For problems containing a crack tip in linear elasticity, the mixed-mode singular near tip stress field can be characterized by a pair of stress intensity factors (SIF's). For isotropic materials, SIFs have been used to predict fatigue crack growth and fracture. Several methods are available to extract the SIF and hence the strain energy release rate (SERR) [12]. Generally, the most useful way to predict the behaviour of a cracked body is using the J-integral method [13]. The J-integral is path-independent for all integral paths surrounding the crack tip. Using this method would require the computation of stresses 
and strains at a series of internal points around the crack, for evaluation of the path-independent integrals, which is obviously time consuming.

For elastic problems the $\mathrm{J}_{1}$-integral is the energy release rate per unit extension of the crack. In conjunction with the Finite Element Method (FEM) or BEM, it is possible to use the shape sensitivity analysis to directly evaluate the sensitivity of the total strain energy where the crack length is being treated as the shape variable. This approach has been used by a few researchers [14-16] who have mainly studied the line cracks in homogeneous and isotropic materials. However, in conjunction with the FEM, Reddy and Rao [16] used the continuum shape sensitivity analysis of a mixed-mode fracture in functionally graded materials using the FEM.

Shape sensitivity analysis, which is the calculation of quantitative information on how the response of a structure is affected by changes in the variables that define its shape, is a fundamental requirement for shape optimization. Shape optimization is an important area of current development in mechanical and structural design. Computerized procedures using optimization algorithms can iteratively determine the optimum shape of a component while satisfying some objectives, without at the same time violating the design constraints. The BEM being a surface-oriented technique is well suited for shape optimization problems in particular shape sensitivity analysis.

In Ref.[17], a directly differentiated form of the BIE, with respect to boundary point coordinates, was used to calculate stress and displacement derivatives for 2D anisotropic structures. In Ref.[18], the optimal shape design of an anisotropic elastic body of maximum stiffness and minimum weight under specified loadings and using the BEM, was obtained. Using the sensitivities of the elastic compliance, the stiffness of the structure was minimized while constraints were placed on the maximum stress and weight. The objective of the work in Ref.[19] is directed towards the optimal positioning of features in anisotropic structures for maximum stiffness, while the weight remains unchanged. For this purpose, the design sensitivity analysis, with respect to the translation and rotation of the voids of arbitrary shapes using the BEM, was performed. In Ref.[20] the shape sensitivity analysis of composite structures in contact has been carried out by direct differentiation of the structural response, rather than using the finite difference method. The design variables are taken as the coordinates of some nodes on the boundaries of the bodies which are in contact. The selection of the boundary points as the design variables is more general than selecting simple geometrical variables such as radii. The advantage of the proposed method is that it can be applied to any geometry, not just regular shapes. However, when entire segments of the boundary or domain are governed by a single variable such as radius, the relevant velocity terms are applied together in the sensitivity analysis with respect to this variable [19]. The results show the influence of the material properties on the sensitivities of the contact pressure and strain energy of the anisotropic components in contact. To the author's knowledge, no other publications are available on the shape optimization or sensitivities of composite materials using the boundary elements. 
This paper presents the application of the boundary element shape sensitivity for the analysis of two dimensional anisotropic bodies with cracks of arbitrary shapes. The design sensitivity analysis of multi-region domains with anisotropic material properties has been carried out by direct differentiation of the structural response. The length of the crack of arbitrary shape is treated as the shape variable. The shape variable is then associated with the coordinates of a series of boundary nodes located on the crack surfaces. Thus, the relevant velocity terms are applied together in the sensitivity analysis with respect to that variable to determine the derivatives of displacements, stresses and the elastic compliance of the structure with respect to the crack extension. Following the calculation of the rate of energy released per unit of crack extension, and the related material property parameters of a composite material, the SIFs of the structure in single or mixed mode loading conditions are determined. The paper shows the advantage of using the boundary element shape sensitivities in crack analysis over the J-integral method, both in terms of the computational modeling and numerical accuracy.

The study on instability analysis of delaminated composite cylindrical shells subject to axial compression, external pressure and bending, either applied individually or in combination [21-23] showed that the SERR was more convenient to be used for the prediction of crack growth and fracture of delaminated composite structures. Here it is shown that although the SIF is of fundamental importance in the prediction of brittle failure using linear elastic fracture mechanics, the SERR for cracked anisotropic meshes has been found to be more convenient for these predictions. Five example problems with anisotropic material properties are presented to validate the applications of this formulation. The results show good agreement with results reported in the literature.

\section{Constitutive equations for plane anisotropic elasticity}

Combining the stress-strain relations, the compatibility equation of strains and the equilibrium equation, the governing equation for the two-dimensional problem of homogeneous and anisotropic elasticity can be obtained [24],

$a_{22} \frac{\partial^{4} \phi}{\partial x_{1}^{4}}-2 a_{26} \frac{\partial^{4} \phi}{\partial x_{1}^{3} \partial x_{2}}+\left(2 a_{12}+a_{66}\right) \frac{\partial^{4} \phi}{\partial x_{1}^{2} \partial x_{2}^{2}}-2 a_{16} \frac{\partial^{4} \phi}{\partial x_{1} \partial x_{2}^{3}}+a_{66} \frac{\partial^{4} \phi}{\partial x_{2}^{4}}=0$

The coefficients $a_{j k}$ are the elastic compliances of the material. For especially orthotropic materials, $\mathrm{a}_{16}=\mathrm{a}_{26}=\mathrm{a}_{63}=0$. [25]. By introducing the operator $\mathrm{D}_{\mathrm{s}}(\mathrm{s}=1,4)$ as

$D_{s}=\frac{\partial}{\partial x_{2}}-\mu_{s} \frac{\partial}{\partial x_{1}}$

Equation (1) becomes

$D_{1} D_{2} D_{3} D_{4}(\phi)=0$.

and $\mu_{\mathrm{s}}$ are the four roots of the characteristic equation

$\left[a_{22}-2 \mu a_{26}+\left(2 a_{12}+a_{66}\right) \mu^{2}-2 a_{16} \mu^{3}+a_{11} \mu^{4}\right] \frac{d^{4} \phi}{d z^{4}}=0$. 
To have a solution for the stress function, the term in square brackets must be zero. Lehknitskii [25] has shown that, for an anisotropic material, these roots are distinct and must be purely imaginary or complex and they may be denoted by

$\mu_{1}=\alpha_{1}+i \beta_{1} \quad, \quad \mu_{1}=\alpha_{2}+i \beta_{2} \quad, \quad \mu_{3}=\bar{\mu}_{1} \quad, \quad \mu_{4}=\bar{\mu}_{2}$

where $\alpha_{\mathrm{j}}$ and $\beta_{\mathrm{j}}(\mathrm{j}=1,2)$ are real constants, $i=\sqrt{-1}$ and the overbar represents the complex conjugate. Therefore, the stresses and displacements in an anisotropic body can be expressed in terms of the complex coordinates $\left(\mathrm{z}_{\mathrm{j}}\right)$

$z_{j}=x_{1}+\mu_{j} x_{2} \quad j=1,2$

and their complex conjugates.

\section{Anisotropic fracture mechanics}

The SIF is of fundamental importance in the prediction of brittle failure using linear elastic fracture mechanics (LEFM). It is a function of both the cracked geometry and the associated loading. $\mathrm{K}_{\mathrm{I}}$ and $\mathrm{K}_{\mathrm{II}}$ are the Mode I and Mode II SIFs, respectively. They characterise the stress fields in the vicinity of the crack tip with respect to a local Cartesian $\left(\mathrm{x}_{1}-\mathrm{x}_{2}\right)$ system which has its origin at the tip of the crack and is oriented with the angle of $\varphi$ with respect to the global Cartesian system(x-y). See Fig. 1.

The J-integral method was first developed by Rice [13] to characterize fracture for two dimensional configurations modeled by a linear or nonlinear elastic material. For such a material of unit thickness containing a traction free crack, the $\mathrm{J}_{\mathrm{k}}$ integral is defined as

$$
J_{k}=\oint_{c}\left(W n_{k}-t_{i} u_{j, k}\right) d s
$$

where $\mathrm{j}, \mathrm{k}=1,2, \mathrm{~W}$ is the strain energy density, $\mathrm{S}$ is a generic contour surrounding the crack tip, $\mathrm{t}_{\mathrm{i}=\sigma_{\mathrm{ij}}} \mathrm{n}_{\mathrm{i}}$ are the traction components defined along the contour and $n_{i}$ are the components of the unit outward normal to the contour path, as shown in Fig. 1. The $\mathrm{J}_{1}$-integral is the Rice's path independent integral. Using the J-integral method, a circular path may be generated with the centre at the crack tip, defining the number of internal points to be computed, beginning on one crack face and finishing on the other. With the numerical integration of equation (7), $\mathrm{J}_{1}$ can then be determined.

$\mathrm{J}_{1}$ is also equal to the rate of energy released per unit of crack extension along the $\mathrm{x}_{1}$ axis. If the length of the crack of arbitrary shape is treated as the shape design variable, then the SERR which is the derivative of the elastic compliance of the structure with respect to the crack length extension is evaluated by direct differentiation of the boundary integral equation (BIE).

The $\mathbf{J}_{1}$-integral is related to the SIFs of a cracked homogeneous anisotropic plate by [6]

$J_{1}=\alpha_{11}^{\prime} K_{I}^{2}+\alpha_{12}^{\prime} K_{I} K_{I I}+\alpha_{22}^{\prime} K_{I I}^{2}$

Where 


$$
\begin{aligned}
& \alpha_{11}^{\prime}=-\frac{a_{22}^{\prime}}{2} \operatorname{Im}\left(\frac{s_{1}+s_{2}}{s_{1} s_{2}}\right) \\
& \alpha_{22}^{\prime}=\frac{a_{11}^{\prime}}{2} \operatorname{Im}\left(s_{1}+s_{2}\right) \\
& \alpha_{12}^{\prime}=-\frac{a_{22}^{\prime}}{2} \operatorname{Im}\left(\frac{1}{s_{1} s_{2}}\right)+\frac{a_{11}^{\prime}}{2} \operatorname{Im}\left(s_{1} s_{2}\right)
\end{aligned}
$$

In equations (9), $s_{1}$ and $s_{2}$ are the material property parameters which are related to the roots of the characteristic equation 4 as follows,

$s_{j}=\frac{\mu_{j} \cos \varphi+\sin \varphi}{\cos \varphi-\mu_{j} \sin \varphi} \quad j=1,2$

Where the $\mathrm{a}_{\mathrm{ij}}^{\prime} \mathrm{s}$ are the compliance constants obtained from the transformation of $\mathrm{a}_{\mathrm{jk}}$ from the global system, to the local coordinate system, as follows[7];

$a_{11}^{\prime}=a_{11} \cos ^{4} \varphi+\left(2 a_{12}+a_{66}\right) \sin ^{2} \varphi \cos ^{2} \varphi+a_{22} \sin ^{4} \varphi+\left(a_{16} \cos ^{2} \varphi+a_{26} \sin ^{2} \varphi\right) \sin 2 \varphi$

$a_{22}^{\prime}=a_{11} \sin ^{4} \varphi+\left(2 a_{12}+a_{66}\right) \sin ^{2} \varphi \cos ^{2} \varphi+a_{22} \cos ^{4} \varphi-\left(a_{16} \cos ^{2} \varphi+a_{26} \sin ^{2} \varphi\right) \sin 2 \varphi$

$a_{12}^{\prime}=a_{12}+\left(a_{11}+a_{22}-2 a_{12}-a_{66}\right) \sin ^{2} \varphi \cos ^{2} \varphi+\frac{1}{2}\left(a_{26}-a_{16}\right) \sin 2 \varphi \cos 2 \varphi$

$a_{66}^{\prime}=a_{66}+2\left(a_{11}+a_{22}-2 a_{12}-a_{66}\right) \sin ^{2} 2 \varphi+2\left(a_{26}-a_{16}\right) \sin 2 \varphi \cos 2 \varphi$

$a_{16}^{\prime}=\left[a_{22} \sin ^{2} \varphi-a_{11} \cos ^{2} \varphi+\frac{1}{2}\left(2 a_{12}+a_{66}\right) \cos 2 \varphi\right] \sin 2 \varphi+\left(a_{16} \cos ^{2} \varphi\right)\left(\cos ^{2} \varphi-3 \sin ^{2} \varphi\right)+$

$\left(a_{26} \sin ^{2} \varphi\right)\left(3 \cos ^{2} \varphi-\sin ^{2} \varphi\right)$

$a_{26}^{\prime}=\left[a_{22} \cos ^{2} \varphi-a_{11} \sin ^{2} \varphi-\frac{1}{2}\left(2 a_{12}+a_{66}\right) \cos 2 \varphi\right] \sin 2 \varphi+\left(a_{16} \sin ^{2} \varphi\right)\left(3 \cos ^{2} \varphi-\sin ^{2} \varphi\right)+$

$\left(a_{26} \cos ^{2} \varphi\right)\left(\cos ^{2} \varphi-3 \sin ^{2} \varphi\right)$

For isotropic materials, $\alpha_{11}^{\prime}=\alpha_{22}^{\prime}=\frac{1}{E}, \alpha_{12}^{\prime}=0$., therefore,

$J_{1}=\frac{K_{I}^{2}+K_{I I}^{2}}{E}$

For decoupling of $\mathrm{K}_{\mathrm{I}}$ and $\mathrm{K}_{\mathrm{II}}$, an auxiliary relationship in terms of displacements ratio can be developed to be used together with $J_{1}$. The displacements on the crack surface $(\theta= \pm \pi)$ near the crack tip of a two dimensional anisotropic body, may be written in the form [8]

$\left[\begin{array}{l}u_{1} \\ u_{2}\end{array}\right]=\sqrt{\frac{2 r}{\pi}}\left[\begin{array}{ll}D_{11} & D_{12} \\ D_{21} & D_{22}\end{array}\right]\left[\begin{array}{l}K_{I} \\ K_{I I}\end{array}\right]$

Where 


$$
\begin{array}{ll}
D_{11}=\operatorname{Im}\left(\frac{s_{2} r_{11}^{\prime}-s_{1} r_{12}^{\prime}}{s_{1}-s_{2}}\right), & D_{12}=\operatorname{Im}\left(\frac{r_{11}^{\prime}-r_{12}^{\prime}}{\mu_{1}-\mu_{2}}\right) \\
D_{21}=\operatorname{Im}\left(\frac{s_{2} r_{21}^{\prime}-s_{1} r_{22}^{\prime}}{s_{1}-s_{2}}\right), & D_{22}=\operatorname{Im}\left(\frac{r_{21}^{\prime}-r_{22}^{\prime}}{s_{1}-s_{2}}\right)
\end{array}
$$

Which shows the coupling of $\mathrm{K}_{\mathrm{I}}$ and $\mathrm{K}_{\mathrm{II}}$ for mixed mode problems in anisotropic bodies. $\mathrm{r}_{\mathrm{ij}}{ }_{\mathrm{j}}$ is defined as follows;

$$
\begin{aligned}
& r_{1 j}^{\prime}=a_{11}^{\prime} s_{j}^{2}+a_{12}^{\prime}-a_{16}^{\prime} s_{j} \\
& r_{2 j}^{\prime}=a_{12}^{\prime} s_{j}+a_{22}^{\prime} / s_{j}-a_{26}^{\prime}
\end{aligned}
$$

If $\delta_{1}$ and $\delta_{2}$ are the relative sliding and opening displacements for $\theta= \pm \pi$, respectively, then

$$
\begin{aligned}
& \delta_{1}=2 \sqrt{\frac{2 r}{\pi}}\left(D_{11} K_{I}+D_{12} K_{I I}\right) \\
& \delta_{2}=2 \sqrt{\frac{2 r}{\pi}}\left(D_{21} K_{I}+D_{22} K_{I I}\right)
\end{aligned}
$$

The ratio of relative displacements is

$$
C=\frac{\delta_{2}}{\delta_{1}}=\frac{D_{21} K_{I}+D_{22} K_{I I}}{D_{11} K_{I}+D_{12} K_{I I}}
$$

and the ratio of stress intensity factors

$$
F=\frac{K_{I}}{K_{I I}}=\frac{C D_{12}-D_{22}}{D_{21}-C D_{11}}
$$

or

$$
K_{I}=F K_{I I}
$$

Once $\mathrm{J}_{1}$ or the derivative of the strain energy with respect to the crack length extension is obtained then $\mathrm{K}_{\mathrm{II}}$ can be obtained by substituting equation (19) into (8).

$$
K_{I I}=\left(\frac{J_{1}}{\alpha_{11}^{\prime} F^{2}+\alpha_{12}^{\prime} F+\alpha_{22}^{\prime}}\right)^{1 / 2}
$$

\section{Review of the boundary element method for anisotropic elasticity}

The analytical formulation of the direct BIE for plane anisotropic elasticity may be developed by following the same steps as in the isotropic case [3].

The BEM is based on the unit load solutions in an infinite body, known as the fundamental solutions, used with the reciprocal work theorem and appropriate limit operations. The BIE of the anisotropic materials is an integral constraint equation relating boundary tractions $\left(\mathrm{t}_{\mathrm{j}}\right)$ and boundary displacements $\left(\mathrm{u}_{\mathrm{j}}\right)$ and it may be written as 


$$
C_{j k} u_{j}(P)+\int_{s} T_{j k}(P, Q) u_{j}(Q) d s(Q)=\int_{s} U_{j k}(P, Q) t_{j}(Q) d s(Q) \quad j, k=1,2
$$

$\mathrm{P}\left(\zeta_{1}, \zeta_{2}\right)$ and $\mathrm{Q}\left(\mathrm{x}_{1}, \mathrm{x}_{2}\right)$ are the field and load points, respectively. $\mathrm{U}_{\mathrm{jk}}(\mathrm{P}, \mathrm{Q})$ and $\mathrm{T}_{\mathrm{jk}}(\mathrm{P}, \mathrm{Q})$ are the fundamental solutions that represent the displacements and tractions, respectively, in the $\mathrm{x}_{\mathrm{k}}$ direction at $\mathrm{Q}$ because of a unit load in the $\mathrm{x}_{\mathrm{j}}$ direction at $\mathrm{P}$ in an infinite body. The constant $\mathrm{C}_{\mathrm{jk}}$ depends on the local geometry of the boundary at $\mathrm{P}$, whether it lies on a smooth surface or a sharp corner. In terms of the generalized complex variables

$$
\begin{aligned}
& z_{1}=\left(x_{1}-\zeta_{1}\right)+\mu_{1}\left(x_{2}-\zeta_{2}\right) \\
& z_{2}=\left(x_{1}-\zeta_{1}\right)+\mu_{2}\left(x_{2}-\zeta_{2}\right)
\end{aligned}
$$

the fundamental solutions for displacements and tractions, respectively, can be written as

$$
\begin{aligned}
& U_{j k}=2 \operatorname{Re}\left[r_{k 1} A_{j 1} \ln \left(z_{1}\right)+r_{k 2} A_{j 2} \ln \left(z_{2}\right)\right] \\
& T_{j 1}=2 n_{1} \operatorname{Re}\left[\mu_{1}^{2} A_{j 1} / z_{1}+\mu_{2}^{2} A_{j 2} / z_{2}\right]-2 n_{2} \operatorname{Re}\left[\mu_{1} A_{j 1} / z_{1}+\mu_{2} A_{j 2} / z_{2}\right] \\
& T_{j 2}=-2 n_{1} \operatorname{Re}\left[\mu_{1} A_{j 1} / z_{1}+\mu_{2} A_{j 2} / z_{2}\right]+2 n_{2} \operatorname{Re}\left[A_{j 1} / z_{1}+A_{j 2} / z_{2}\right]
\end{aligned}
$$

where $\mathrm{n}_{\mathrm{j}}$ are the unit outward normal components at $\mathrm{Q}$ with respect to the $\mathrm{x}_{1}-\mathrm{x}_{2}$ coordinate system. The constants $\mathrm{r}_{\mathrm{kj}}$ are

$$
\begin{aligned}
& r_{1 j}=a_{11} \mu_{j}^{2}+a_{12}-a_{16} \mu_{j} \\
& r_{2 j}=a_{12} \mu_{j}+a_{22} / \mu_{j}-a_{26}
\end{aligned}
$$

and $\mathrm{A}_{\mathrm{jk}}$ are complex constants that can be obtained from the following set of equations:

$$
\begin{aligned}
& A_{j 1}-\bar{A}_{j 1}+A_{j 2}-\bar{A}_{j 2}=\delta_{j 2} / 2 \pi i \\
& \mu_{1} A_{j 1}-\bar{\mu}_{1} \bar{A}_{j 1}+\mu_{2} A_{j 2}-\bar{\mu}_{2} \bar{A}_{j 2}=-\delta_{j 1} / 2 \pi i \\
& r_{11} A_{j 1}-\bar{r}_{11} \bar{A}_{j 1}+r_{21} A_{j 2}-\bar{r}_{21} \bar{A}_{j 2}=0 . \\
& r_{12} A_{j 1}-\bar{r}_{12} \bar{A}_{j 1}+r_{22} A_{j 2}-\bar{r}_{22} \bar{A}_{j 2}=0 .
\end{aligned}
$$

An elastic body with several cracks may be divided into several sub-regions where the crack faces coincide with the boundaries of the sub-regions. The multi-region modeling approach was first exploited for crack modeling by Blandford et al[26] where BIE (Eq.21) is employed individually for each sub-region(L) in turn.

$$
C_{j k}^{(L)} u_{j}^{(L)}(P)+\int_{s(L)} T_{j k}^{(L)}(P, Q) u_{j}^{(L)}(Q) d s^{(L)}(Q)=\int_{s} U_{j k}^{(L)}(P, Q) t_{j}^{(L)}(Q) d s^{(L)}(Q) \quad j, k=1,2
$$

The boundary-element implementation of equation (26) entails boundary discretization. Quadratic isoparametric elements can be employed for the analyses. Substitution of these isoparametric representations into equation (26) will result in a set of linear algebraic equations for the unknown displacements and tractions at the nodes on the boundary of the solution domain as follows:

$A U=B$

where $\mathrm{A}$ is the final coefficient matrix, $\mathrm{U}$ is a vector containing the unknown displacements or tractions. The second member B is a vector which consists of all the known values multiplied by corresponding matrix elements. Then appropriate continuity and equilibrium conditions are applied at 
the common sub-region interface before the linear algebraic equations are solved. For example for two sub-regions, $\mathrm{R}_{\mathrm{a}}$ and $\mathrm{R}_{\mathrm{b}}$, respectively,

$$
u_{i}^{R a}=u_{i}^{R b} \quad, \quad t_{i}^{R a}+t_{i}^{R b}=0
$$

\section{Sensitivities of the structural response for a multi-region domain}

In the recent study by the author a directly differentiated form of BIE with respect to geometric design variables was used to calculate shape design sensitivities for anisotropic materials with frictionless contact [20]. The selected design variables were the coordinates of the boundary points either in the contact or non-contact area. The selection of the boundary points as the design variables was more general than selecting simple geometrical variables such as radii, etc. The advantage of the proposed method was that it can be applied to any geometry, not necessarily regular shapes. However, when entire segments of the boundary or domain were governed by a single variable such as radius, the relevant velocity terms were applied together in the sensitivity analysis with respect to that variable [19] to determine the gradients of the objective function and the constraints. It was shown that, if the entire boundary is governed by a single geometric variable $(\omega)$, such as radius, the material derivative $\mathrm{F}^{\prime}$ with respect to the variable can be written as

$\frac{d F}{d \omega}=\frac{\partial F}{\partial \omega}+\frac{\partial F}{\partial x_{i}} \frac{\partial x_{i}}{\partial \omega}$

$\frac{\partial F}{\partial \omega}$ is equal to zero because the shape variables are not explicit terms in the BIE. $\partial \mathrm{F} / \partial \mathrm{x}_{\mathrm{i}}$ are derivatives of the function $\mathrm{F}$ with respect to the coordinates of the nodes located on the boundary. $\partial \mathrm{x}_{\mathrm{i}} / \partial \omega$ can be obtained by the definition of appropriate relations between the boundary point coordinates and the geometric variable $(\omega)$. The function $\mathrm{F}$ can be the elastic compliance of the structure, contact stress, displacement, etc.

Here, using a similar approach the crack length of arbitrary geometric shape is selected as the shape design variable. Then, the shape variable is associated with the coordinates of a series of boundary nodes located on the crack surface. Thus, the relevant velocity terms are applied together in the sensitivity analysis with respect to that variable to determine the gradients of the elastic compliance or the SERR with respect to the crack length extension. The following shows how the sensitivities of displacements, stresses and elastic compliance with respect to the boundary point coordinates for a multi-region domain are calculated.

Direct differentiation of the BIE for each sub-region with respect to a design variable, $\mathrm{x}_{\mathrm{h}}(\mathrm{h}=1,2)($ which is most likely to be the coordinate of a node on the crack surface) results in the following equation: 


$$
\begin{aligned}
& C_{j k}^{(L)} \frac{\partial u_{j}^{(L)}(P)}{\partial x_{h}}+\frac{\partial C_{j k}^{(L)}}{\partial x_{h}} u_{j}^{(L)}(P)+\int_{s(L)}\left[\frac{\partial T_{j k}^{(L)}(P, Q)}{\partial x_{h}} u_{j}^{(L)}(Q)+T_{j k}^{(L)}(P, Q) \frac{\partial u_{j}^{(L)}(Q)}{\partial x_{h}}\right] d s^{(L)}(Q)+ \\
& \int_{s(L)}\left[T_{j k}^{(L)}(P, Q) u_{j}^{(L)}(Q)\right] \frac{\partial\left[d s^{(L)}(Q)\right]}{\partial x_{h}}=\int_{s(L)}\left[\frac{\partial U_{j k}^{(L)}(P, Q)}{\partial x_{h}} t_{j}^{(L)}(Q)+U_{j k}^{(L)}(P, Q) \frac{\partial t_{j}^{(L)}(Q)}{\partial x_{h}}\right] d s^{(L)}(Q) \\
& \int_{s} U_{j k}^{(L)}(P, Q) t_{j}^{(L)}(Q) \frac{\partial\left[d s^{(L)}(Q)\right]}{\partial x_{h}} \quad j, k=1,2
\end{aligned}
$$

The derivatives of the terms that only depend on the geometry will be carried out similar to the isotropic materials [27]. The derivatives of the kernels for anisotropic materials will be as follows [17]:

$$
\begin{aligned}
\frac{\partial U_{j k}}{\partial x_{h}} & =2 \frac{\partial}{\partial x_{h}}\left[\operatorname{Re}\left(r_{k 1} A_{j 1} \ln \left(z_{1}\right)+r_{k 2} A_{j 2} \ln \left(z_{2}\right)\right)\right] \\
\frac{\partial T_{j 1}}{\partial x_{h}} & =2 n_{1} \frac{\partial}{\partial x_{h}}\left[\operatorname{Re}\left(\frac{\mu_{1}^{2} A_{j 1}}{z_{1}}+\frac{\mu_{2}^{2} A_{j 2}}{z_{2}}\right)\right]+2 \operatorname{Re}\left(\frac{\mu_{1}^{2} A_{j 1}}{z_{1}}+\frac{\mu_{2}^{2} A_{j 2}}{z_{2}}\right) \frac{\partial\left(n_{1}\right)}{\partial x_{h}} \\
& -2 n_{2} \frac{\partial}{\partial x_{h}}\left[\operatorname{Re}\left(\frac{\mu_{1} A_{j 1}}{z_{1}}+\frac{\mu_{2} A_{j 2}}{z_{2}}\right)\right]-2 \operatorname{Re}\left(\frac{\mu_{1} A_{j 1}}{z_{1}}+\frac{\mu_{2} A_{j 2}}{z_{2}}\right) \frac{\partial\left(n_{2}\right)}{\partial x_{h}} \\
\frac{\partial T_{j 2}}{\partial x_{h}} & =-2 n_{1} \frac{\partial}{\partial x_{h}}\left[\operatorname{Re}\left(\frac{\mu_{1} A_{j 1}}{z_{1}}+\frac{\mu_{2} A_{j 2}}{z_{2}}\right)\right]-2 \operatorname{Re}\left(\frac{\mu_{1} A_{j 1}}{z_{1}}+\frac{\mu_{2} A_{j 2}}{z_{2}}\right) \frac{\partial\left(n_{1}\right)}{\partial x_{h}} \\
& +2 n_{2} \frac{\partial}{\partial x_{h}}\left[\operatorname{Re}\left(\frac{A_{j 1}}{z_{1}}+\frac{A_{j 2}}{z_{2}}\right)\right]+2 \operatorname{Re}\left(\frac{A_{j 1}}{z_{1}}+\frac{A_{j 2}}{z_{2}}\right) \frac{\partial\left(n_{2}\right)}{\partial x_{h}}
\end{aligned}
$$

The coefficients $\mu_{\mathrm{j}}$ and $\mathrm{A}_{\mathrm{jk}}$ depend on the material properties and are independent of the boundary nodes coordinates. To calculate the preceding derivatives, the complex values, $\ln \left(\mathrm{z}_{\mathrm{j}}\right)$ and $\left(1 / \mathrm{z}_{\mathrm{j}}\right)$ can be written as

$$
\ln \left(z_{j}\right)=\ln \left|z_{j}\right|+i \arg \left(z_{j}\right) \quad, \quad \frac{1}{z_{j}}=\frac{\bar{z}_{j}}{\left|z_{j}\right|^{2}}
$$

Defining the real functions $\Lambda_{\mathrm{j}}, \Omega_{\mathrm{j}}$ as,

$$
\begin{aligned}
& \Lambda_{1}=\left(x_{1}-\zeta_{1}\right)+\alpha_{1}\left(x_{2}-\zeta_{2}\right) \\
& \Lambda_{2}=\left(x_{1}-\zeta_{1}\right)+\alpha_{2}\left(x_{2}-\zeta_{2}\right) \\
& \Omega_{1}=-\beta_{1} \zeta_{2}+\beta_{1} x_{2} \\
& \Omega_{2}=-\beta_{2} \zeta_{2}+\beta_{2} x_{2}
\end{aligned}
$$

The complex coordinates and their conjugates can be written as

$$
z_{j}=\Lambda_{j}+i \Omega_{j} \quad, \quad \bar{z}_{j}=\Lambda_{j}-i \Omega_{j}
$$

By substituting equations (32-34) into equations (31), the derivatives of the kernel products with respect to the design variable $\mathrm{x}_{\mathrm{h}}$ can be obtained. 
For calculation of the sensitivities of an elastic body which is divided into several sub-regions, the boundary constraints, equation 28 , must be differentiated with respect to the design variable. The differentiated form of the boundary constraints will create relationships between the derivatives of the displacements and tractions of the node pairs. For the stick node pair $(\mathrm{Na}, \mathrm{Nb})$ the differentiated form of equation 28 is,

$$
\frac{d u_{i}^{N a}}{d x_{h}}+\frac{d}{d x_{h}}\left(x_{i}^{N a}\right)=\frac{d u_{i}^{N b}}{d x_{h}}+\frac{d}{d x_{h}}\left(x_{i}^{N b}\right) \quad, \quad \frac{d t_{i}^{N a}}{d x_{h}}+\frac{d t_{i}^{N b}}{d x_{h}}=0 . \quad i=1,2
$$

Thus, the design sensitivity analysis is carried out by direct differentiation of the structural response (Eq. 27) with respect to design variables.

$$
\frac{\partial A}{\partial x_{h}} U+A \frac{\partial U}{\partial x_{h}}=\frac{\partial B}{\partial x_{h}} \Rightarrow A \frac{\partial U}{\partial x_{h}}=\left(\frac{\partial B}{\partial x_{h}}-\frac{\partial A}{\partial x_{h}} U\right)
$$

This is a set of linear algebraic equations for the unknown gradients, $\frac{\partial U}{\partial x_{h}}$, and equivalent to solving the same equation as equation 27. Thus, if the quantity in brackets in equation 36 is separately assembled, then the derivatives of displacements and tractions can be computed in one pass by reentering the equation solver. Following the calculation of displacement gradients, the gradients of stresses can be obtained [17].

The elastic compliance is evaluated as the strain energy of the structure

$$
E_{s}=\frac{1}{2} \int_{s} t_{j} u_{j} d s
$$

The derivatives of the elastic compliance, with respect to the boundary point coordinate, $\mathrm{x}_{\mathrm{h}}$, can also be calculated analytically as follows:

$$
\frac{\partial E_{s}}{\partial x_{h}}=\frac{1}{2}\left[\int_{s} \frac{\partial t_{j}}{\partial x_{h}} u_{j} d s+\int_{s} t_{j} \frac{\partial u_{j}}{\partial x_{h}} d s+\int_{s} u_{j} t_{j} \frac{\partial}{\partial x_{h}} d s\right]
$$

Equation 38 shows that during the analysis, the compliance derivatives are calculated after, the tractions, displacements and their derivatives are obtained [18].

\section{Results and discussuion}

The method presented here has been applied to several mode I and mixed mode crack problems to compare its accuracy for different loading conditions and material properties. The engineering constants of the selected materials for the analysis are shown in Table 1. Every component is being treated as a lamina that has four engineering constants, $E_{1}, E_{2}, G_{12}$ and $v_{12}$ with a lamina orientation angle of zero. When the fibre orientation is greater than zero the equivalent engineering constants are determined and subsequently used in the analysis. Aluminium is an isotropic material but in the 
current analysis it is assumed as if it is anisotropic $\left[\mathrm{E}_{1}=\mathrm{E}_{2}, \mathrm{G}_{12}=0.5 \times \mathrm{E}_{1}\left(1+\mathrm{v}_{12}\right)\right]$. In each case the meshes were refined to assure the convergence of the solution.

Five examples are analysed and the results are presented as follows: a rectangular plate with a central crack subject to tensile stresses at the ends, a cantilever plate with a single edge crack loaded by shear stresses at its free end, a rectangular plate with a single edge crack or central slant crack subject to tension and finally a circular arc crack in an infinite plate subject to equi-biaxial tension. See figures 26 respectively.

The first example analysed is an isotropic thin flat plate with a central crack of length, $2 \mathrm{a}$, and width, $2 \mathrm{w}$, subjected to tensile stresses $(\sigma)$ at the ends of the plate, as shown in Fig. 2. Due to symmetric boundary conditions, only a quarter of the plate needs to be analysed. The BE mesh consists of 48 elements where 40 elements were placed on the edge AB. The crack length is the only shape variable of this model. As explained in section 5, the shape variable is associated with the coordinates of a series of boundary nodes located on the crack surfaces, related to the boundary element discretization of the structure. If $(\omega)$ in equation 29 is the crack length, then coordinates of each boundary point on the crack face is $x_{i}=\omega n_{i}$, where $\mathrm{n}_{\mathrm{i}}$ is the fixed direction cosine at the boundary. Therefore, for each boundary point $x_{i}^{\prime}=\partial x_{i} / \partial \omega=n_{i}$.

Initially the sensitivity of the elastic compliance with respect to the crack length extension, which is equal to the SERR or $\mathrm{J}_{1}$ is determined. The plate is loaded in mode $\mathrm{I}$. Therefore, $\mathrm{K}_{\mathrm{II}}=0$. and using equation(8), $\mathrm{K}_{\mathrm{I}}$ can be obtained. Fig. 7 shows the variation of the SERR with respect to the crack length $(\mathrm{a} / \mathrm{w})$ obtained numerically, where $\mathrm{a} / \mathrm{w}$ varies from 0.1 to 0.5 . The corresponding SIF values are shown in Table 2.

There is an analytical solution for this example which gives $\mathrm{K}_{\mathrm{I}}$ in terms of the normalized crack length $(\mathrm{a} / \mathrm{w})$ [28]

$$
K_{I}=K_{0} \frac{1-\frac{a}{2 w}+0.326 \frac{a^{2}}{w^{2}}}{\sqrt{1-\frac{a}{w}}}
$$

where $K_{0}=\sigma \sqrt{\pi a}$. By substituting $\mathrm{K}_{\mathrm{I}}$ from equation (39) into equation (12) the value of SERR can be obtained as follows:

$$
J_{1}=\frac{1}{E}\left(K_{0} \frac{1-\frac{a}{2 w}+0.326 \frac{a^{2}}{w^{2}}}{\sqrt{1-\frac{a}{w}}}\right)^{2}
$$


Table 2 shows the analytical values of $\mathrm{K}_{\mathrm{I}}$ for different ratios of a/w obtained using equation 39 . Fig. 7 shows the variation of SERR with respect to a/w obtained using equation 40 . It can be observed that the present numerical results are in very good agreement with the analytical solution.

Next, the same plate with a central crack, but made of material No. 2, is analysed, where $E_{1}=G_{12}\left(\phi+2 v_{12}+1\right)$, the shear modulus, $\mathrm{G}_{12}$, and the Poisson's ratio, $v_{12}$, have fixed values of $6 \mathrm{GPa}$ and 0.03 , respectively. The parameter $\phi=\mathrm{E}_{1} / \mathrm{E}_{2}$ varies from 0.1 to 4.5 . The crack length to width ratios of $\mathrm{a} / \mathrm{w}=0.2,0.5$ and 0.8 are considered. This example was also studied by Bowie and Freeze[5] where they used the modified mapping collocation technique and Sollero and Aliabadi [8] where they employed the J-integral in-conjunction with the BEM. Here with their SIFs [5,8] and using equation 13 the corresponding SERR values are calculated and compared with the SERR values obtained using the shape sensitivities.

Figs. 8 and 9 show the variations of the normalized SIFs and the SERR of the plate with respect to the change of $\phi$, respectively. It can be observed that the present results are in very good agreement with the results published in references [5] and [8]. However, for $\mathrm{a} / \mathrm{w}=0.8$, when $\phi>1.0$, there is a slight discrepancy in the SERR and SIF values obtained by Bowie and Freeze[5]. The results show that for a given crack length, when $\phi>1.0$, the SERR and the SIFs are almost independent of the value of $\phi$. For $\phi<1$, as $\phi$ decreases, the SERR decreases whereas the SIFs increase. This is due to the fact that the load is applied in the $\mathrm{E}_{2}$ direction and $\phi$ is proportional to the invert of $\mathrm{E}_{2}$.

The next example is a rectangular plate of width $w$ with a single edge crack of $a / w=0.5$. Material No. 3 is selected for the analysis which is graphite-epoxy where the direction of fibres are rotated from $\psi=0^{\circ}$ to $\psi=90^{\circ}$. The plate is divided into two sub-regions where continuity of the traction and displacement along BC, according to equations 28, is considered. The BE mesh of each region consists of 49 elements of which 40 elements were placed on edge AC. Two types of loadings are studied. Fig. 3 shows the plate which is clamped at one end and loaded by a uniform shear force of $\tau_{0}$ at the free end. Fig. 4 shows the same plate which is subject to tensile stresses $(\sigma)$ at both ends.

Fig. 10 shows the variation of normalized modes I and II SIFs with respect to the fibre orientation $(\psi)$ for the cantilever plate subject to shear, where $K_{0}=\tau_{0} \sqrt{\pi a}$. This example was also studied by Chu and Hong[6] and also Sollero and Aliabadi [8], where they employed the J-integral in-conjunction with the FEM[6] or BEM[8], respectively. Their results are included in Fig. 10 which are in very good agreement with the present findings. Fig. 11 shows the variation of SERR with respect to the fibre angle obtained from the present study and those calculated from the SIF values published in references [6] and [8]. It can be seen that the present results are in very good agreement with those obtained by Sollero and Aliabadi[8]. However, for $\psi<30^{\circ}$ there is a slight discrepancy in the results produced by Chu and Hong[6]. It can be observed that there is a small variation of the normalized SIFs with respect 
to the fibre angle. $\mathrm{K}_{\mathrm{I}} / \mathrm{K}_{0}$ changes from a minimum value of 8.67 to a maximum value of 9.42 while $\mathrm{K}_{\mathrm{II}} / \mathrm{K}_{0}$ varies from 0.97 to 1.40 . The variation of the SERR with respect to the fibre angle is more evident. For $\psi<30^{\circ}$ the SERR is almost independent of the fibre angle. For $\psi>30^{\circ}$ there is a sharp drop in the SERR, and the higher the fibre angle, the lower the SERR. For $\psi=90^{\circ}$ the SERR has the least value, as expected.

Fig. 12 shows the variation of the SERR with respect to the fibre angle when the plate is subjected to tension at its ends(Fig. 4). The corresponding normalized mode I SIFs of the plate are included in Fig. 10. It can be observed that for $\psi<20^{\circ}$ the SERR is almost independent of the fibre angle and after a slight increase of SERR, when $20^{\circ}<\psi<30^{\circ}$, there is a sharp drop in the SERR. The SERR has the least value when the load is applied along the fibre direction $\left(\psi=90^{\circ}\right)$, as expected.

For both loading cases, the normalized SIF values with isotropic material properties (material No. 1) are also obtained and presented in Fig. 10. It can be observed that for the cantilever plate, when $\psi<60^{\circ}$, $\mathrm{K}_{\mathrm{II}}$ is almost independent of the material property of the cantilever plate. For the plate subject to tension, when $\psi>30^{\circ}, \mathrm{K}_{\mathrm{I}}$ is almost independent of the material property of the plate.

It can be concluded that although for anisotropic materials the SIF is of fundamental importance in the prediction of brittle failure using linear elastic fracture mechanics, for composite laminates, the direct evaluation of the SERR would easily characterise their crack instability with respect to the fibre orientation.

The next example is a central slant crack of length $\mathrm{a} / \mathrm{w}=0.2$ in a rectangular plate of height to width ratio of $h / w=0.2$ subjected to tension $(\sigma)$. The crack is inclined with the angle of $\phi$ with respect to the plate sides and the fibre orientation varies from $0^{\circ}$ to $120^{\circ}$, as shown in Fig. 5. The plate is divided into two sub-regions and the BE mesh of each region consists of 39 elements of which 30 elements were placed on edge AD. The material is a glass-epoxy composite, material No. 4 in Table 1 . Table 3 shows the normalized SIF values for the crack angle of $\phi=45^{\circ}$ where $K_{0}=\sigma_{0} \sqrt{\pi a}$. The SIF values obtained by Sollero \& Aliabadi[8] and Gandhi [2] are also presented in Table 3, which agree very well with the present results. Ghandi [2] used the modified mapping collocation technique. Fig. 13 shows the variation of SERR with respect to the fibre orientation, obtained using the present method, and those computed from the SIF values reported in references [2] and [8], which are in very good agreement.

In order to examine the effect of the crack orientation angle on the SERR and SIFs, the crack angles of $\phi=0^{\circ}, 30^{\circ}$ and $60^{\circ}$, respectively, were studied, where the crack length was fixed at $\mathrm{a} / \mathrm{w}=0.2$. For each crack direction, the fibre orientation varies from $0^{\circ}$ to $120^{\circ}$. Fig. 13 shows the variation of the SERR with respect to the fibre angle for different crack orientations. Fig. 14 shows the variation of the SERR with respect to the crack orientation angle $(\phi)$ of the plate for different fibre orientations. The results 
show that for any crack orientation angle, the same trend of variation for SERR, with respect to the fibre angle, can be observed. The minimum and maximum values of the SERR occur, when the loads are applied in the fibre direction $\left(\psi=90^{\circ}\right)$ and in the transverse direction of the fibres $(\psi=0)$, respectively For any fibre orientation angle, the maximum SERR occurs when the crack orientation angle is zero and the higher the crack orientation angle, the lower the SERR. For any fibre orientation angle, the crack angle of $\phi=60$ has the least value of SERR, and for this crack direction, the variation of the SERR with respect to the fibre angle is relatively small.

In order to apply the current method for the curved crack geometries, the problem of a crack with a circular arc shape in an unbounded domain is analysed. Fig. 6 shows a circular arc crack with the semiangle of $\beta$, in an infinite plate subject to uniform tension $(\sigma)$ in two perpendicular directions. Materials No. 1 and 5, which are isotropic and graphite-epoxy, respectively, are considered for the analysis. Cracks with semi-angles $10^{\circ}$ to $90^{\circ}$, with an increment of $10^{\circ}$, are modelled and analysed. The plate is divided into two sub-regions and the BE mesh of the regions consist of 60 and 44 elements, respectively, of which 36 elements were placed on each side of the semi-circle edge $\mathrm{ABC}$.

For the plate with isotropic material property (material No. 1), the normalized mode I and II SIF values are computed and compared with those results obtained by Chen [29] and Garcia et al [9]. In Ref.[29] a singular integral equation was developed containing the crack opening displacement for solving plane elasticity problems. He evaluated the SIFs for curved and kinked cracks in plane extension. In Ref. [9] a general mixed mode boundary element approach for anisotropic media is presented where integration of the singular and hyper singular kernels along quadratic line elements is carried out by analytical transformation of the integrals into regular ones. Fig. 15 shows the variations of the SIFs with respect to the crack semi-angle $(\beta)$ using the present method, and those obtained in references [29] and [9], which are in very good agreement. Variation of the SERR with respect to the crack semi-angle is shown in Fig. 16. Using the SIFs in Refs.[9,29] and equation 17, the corresponding SERRs are evaluated and compared with the present findings. The results show that, for the isotropic material, $\mathrm{K}_{\mathrm{II}}$ has an almost linear variation with respect to the crack semi-angle and is at its maximum when the crack semi-angle is $\beta=90^{\circ}$. Fig. 16 shows that the SERR has a nonlinear variation with respect to the crack semi-angle and the maximum SERR occurs when the crack semi-angle is between 55 and 65 degrees. When $\beta<55^{\circ}$ the higher the crack angle, the higher the SERR, but when $\beta>65^{\circ}$, the higher the crack angle, the lower the SERR.

The curved crack with a circular arc shape in an unbounded domain is also analysed with material No. 5, which is graphite-epoxy, where the fibre angle is changing from $\psi=0^{\circ}$ to $90^{\circ}$. Fig. 17 shows the variation of the SERR with respect to the crack semi-angle for different fibre orientations of the graphite-epoxy plate. It can be observed that when fibres are in the y-direction $\left(\psi=90^{\circ}\right)$, the SERR has the lowest value for any crack orientation angle. It is shown that for $\psi=90^{\circ}$, SERR has an almost linear variation with respect to the crack semi-angle and the higher the crack angle, the higher the SERR. For other fibre orientations, the variation of SERR with respect to the crack semi-angle is nonlinear where 
the maximum SERR occurs, when $55^{\circ}<\beta<65^{\circ}$. The SIF values of the plate, with the fibre orientation of $\psi=90^{\circ}$ for different crack angles are computed and compared with those obtained by Wang and Sun[10] where they used integration by parts to the traditional boundary integral formulation for the analysis of the cracked 2D anisotropic bodies. Fig. 18 shows that their results are in very good agreement with the present findings.

Early application of the BEM involving interactions of multiple cracks and rigid lines representing fibres dates back to 1990s [30-33]. The modeling of crack and fibre interactions is essential for a comprehensive model of damage in composites. However, the present study focuses on the crack analysis of a lamina at the macro scale where the equivalent engineering constants are used for the analysis. At present, the most common method used in industry for the crack analysis is the J-Integral in-conjunction with the FEM. The application of the J-integral with the BEM will reduce the time of modeling and analysis but would still require the calculation of stresses and strains at a series of internal points around the crack for evaluation of the path-independent integrals. Using the boundary element shape sensitivities with the design variables which represent the crack surfaces, the computational efficiency will be greatly improved.

\section{Conclusion}

Following a brief review of the mathematical basis of the BIE method for multi-region anisotropic materials, analytical differentiation of the BIE was carried out with respect to the positions of the boundary nodes. Shape design sensitivity analysis for an anisotropic multi-region domain was performed to compute the derivatives of displacements, stresses, elastic compliance, etc with respect to changes of boundary point coordinates. The crack length of arbitrary geometric shape was designated as the shape design variable. Then each shape variable was associated with the coordinates of a series of boundary nodes located on the crack surfaces. Thus, the relevant velocity terms were applied together in the sensitivity analysis with respect to that variable to determine the gradient of the total strain energy of the structure with respect to the crack length extension. In contrast to the J-integral method which would require the computation of stresses and strains at a series of internal points around the crack for evaluation of the path-independent integrals, here the fracture mechanics parameters are evaluated by direct differentiation of the BIE. Therefore, for the same number of elements, not only is the accuracy of the present method very high, but in terms of computational modeling and analysis, it is much more efficient.

The sensitivity analysis algorithm was validated using the test cases with known analytical solutions. Five example problems have been analysed and the results are presented. Five different anisotropic materials were employed for the analysis. The isotropic materials were treated as if they were anisotropic. The results show that although the SIF is of fundamental importance in the prediction of brittle failure using linear elastic fracture mechanics, for composite laminates, the direct evaluation of the SERR would easily characterise their crack instability with respect to the fibre orientation. The results show that the SERR was highly influenced by the fibre orientation of the composite lamina. 
atafreshi@manchester.ac.uk (doi: 10.2514/1.41729, AIAA J.)

Therefore, a laminate can be tailored to crack growth resistance. Due to the flexibility of the present method, the future studies should cover the analysis of multiple curved cracks, kinked cracks and bimaterial interface cracks in composites using the boundary element shape sensitivities. 


\section{References}

[1.] Synder M.D. and Cruse T.A., "Boundary integral equation analysis of cracked anisotropic plates", Int. J. Fract. 1975, 11(2): 315-28

[2.] Gandhi, K.R., "Analysis of an inclined crack centrally placed in an orthotropic rectangular plate", Journal of Strain Analysis, 1972, 7(3): 157-162

[3.] Cruse T A, "Boundary element analysis in computational fracture mechanics" Kluwer, Dordrecht Academic Publishers; 1988

[4.] Hayes, D.J., “A practical application of Buekner's formulation for determining stress intensity factors for cracked bodies”, Int. J. Fracture Mechanics, 1972, 8(2): 157-165

[5.] Bowie, O.L. and Freeze, C.E., "Central crack in plane orthotropic rectangular sheet", International Journal of Frature Mechanics, 1972, 8: 49-58

[6.] Chu, S.J and Hong, C.S., "Application of the $\mathrm{J}_{\mathrm{k}}$ integral to mixed mode crack problems for anisotropic composite laminates", 35(6), 1990: 1093-1103

[7.] Tan, C.L. and Gao, Y.L. "Boundary element analysis of plane anisotropic bodies with stress concentrations and cracks", Composite Structures, 1992: 17-28

[8.] Sollero, P. and Aliabadi, M.H., "Fracture mechanics analysis of anisotropic plates by the boundary element method", International Journal of Fracture, 1993: 64, 269-284

[9.] Garcia, F., Saez, A. and Dominguez, "Traction boundary elements for cracks in anisotropic solids", Engineering Analysis with Boundary Elements, 2004, 28: 667-676

[10.] Y.B Wang and Y.Z. Sun, "A new boundary integral equation method for cracked 2D anisotropic bodies", Engineering fracture mechanics, 2005, 72: 2128-2143

[11.] Chang, J.H and Wu, D.J, "Computation of mixed-mode stress intensity factors for curved cracks in anisotropic elastic solids", Engineering Fracture Mechanics, 2007, 74: 1360-1372

[12.] Parker, A.P., "The mechanics of fracture and fatigue”, E\&F.N. Spon Ltd, 1981

[13.] Rice, J.R., "A path independent integral and the approximate analysis of strain concentration by notches and cracks" Journal of Applied Mechanics, 1968, 35: 379-386 
[14.] Keum, D.J. and Kwak, B.M., "Calculation of stress intensity factors by sensitivity analysis with respect to change of boundary conditions", Computers and Structures, 1992, 44(1/2): 63-69

[15.] Lee, T.W. and Grosse, J.R., "Energy release rate by a shape design sensitivity approach", Engineering Fracture Mechanics, 1993, 44(5): 807-819

[16.] Reddy, R.M. and Rao, B.N., "Continuum shape sensitivity analysis of mixed-mode fracture using fractal finite element method", Engineering Fracture Mechanics, 2008, 75(10): 2860-2906

[17.] Tafreshi A., "Shape design sensitivity analysis of 2D anisotropic structures using the boundary element method”, Engineering Analysis with Boundary Elements, 2002, 26(3): 237-251

[18.] Tafreshi A., "Optimum shape design of composite structures using the boundary element method" AIAA J, 2005, 43(6): 1349-59

[19.] Tafreshi A., "Shape design sensitivity analysis with respect to the positioning of features in composite structures using the boundary element method", Engineering Analysis with boundary elements, 2006, 30: 1-13

[20.] Tafreshi, A., "Shape sensitivity analysis of composites in contact using the boundary element method", Engineering Analysis with boundary elements, 2009, 33(2): 215-224

[21.] Tafreshi, A., "Efficient modelling of delamination in composite cylindrical shells under axial compression", Composite Structures, 2004: 64, 511-520

[22.] Tafreshi, A.,'Instability of delaminated composite cylindrical shells under combined axial compression and bending”, Composite Structures, 2008, 82(3): 422-433

[23.] Tafreshi, A., "Delamination buckling of composite cylindrical shells", Chapter 20, In Delamination buckling of composites edited by S.Sridharan, Washington University in St Louis, Woodhead Publishing, 2008, ISBN 1845692446

[24.] Gibson R F, "Principles of composite material mechanics", McGraw-Hill; 1994

[25.] Lekhnitskii S.G.,"Theory of elasticity of an anisotropic elastic body", Holden-Day; San Fransisco, 1963

[26.] Blandford, G.E., Ingraffea, A.R. and Liggett, "Two-dimensional stress intensity factor computations using the boundary element method", International Journal for Numerical Methods in Engineering, 1981, 17:387-404 
[27.] Tafreshi A. and Fenner R.T., "Design optimization using the boundary element method", J Strain Anal, 1991, 26(4): 231-241

[28.] Solecki, R. and Conant, R.J., “Advanced mechanics of materials”, Oxford University Press, 2003

[29.] Chen, Y.Z., Stress intensity factors for curved and kinked cracks in plane extension", Theoretical and Applied Fracture Mechanics, 1999, 31: 223-232

[30.] Hu, K. X., Chandra, A. and Huang, Y., "On Interacting Bridged-Crack Systems," Int. J. Solids Struc., 1994, 31(5): 599-611

[31.] Chandra, A., Hu, K. X. and Huang, Y., "A Hybrid BEM Formulation for Multiple Cracks in Orthotropic Elastic Components", Computers and Structures, 1995, 56(5): 785-797

[32.] Jiang, Z. Q., Chandra, A. Huang, Y., “A Hybrid Micro-Macro BEM with Micro-Scale InclusionCrack Interactions”, Int. J. Sol. Struct. 1996, 33 (16): 2309-2329

[33.] Huang, Y., Chandra, A., Wei, X., Jiang, Z. Q. Hu, K. X., “A Numerical Calculation of TwoDimensional Moduli for Microcracked Solids”, Int. J. Sol. Struct 1996, 33(11): 1575-1586 
Table 1 Elastic properties of the selected materials

\begin{tabular}{|l|l|l|l|l|l|l|l|}
\hline No. & $\begin{array}{l}\text { Elastic } \\
\text { properties }\end{array}$ & $\begin{array}{l}\mathrm{E}_{\mathrm{L}} \\
\mathrm{GPa}\end{array}$ & $\begin{array}{l}\mathrm{E}_{\mathrm{T}} \\
\mathrm{GPa}\end{array}$ & $\begin{array}{l}\mathrm{v}_{\mathrm{LT}} \\
\mathrm{GPa}\end{array}$ & $\begin{array}{l}\mathrm{G}_{\mathrm{LT}} \\
\mathrm{GPa}\end{array}$ & \multicolumn{2}{|c|}{ Complex parameters } \\
$\mu_{1}$ & $\mu_{2}$ \\
\hline 1 & Aluminium & 70.0 & 70.0 & 0.3 & 26.923 & $\mathrm{i}$ & $\mathrm{i}$ \\
\hline 2 & Hypothetical & $\begin{array}{c}\text { For } \phi=0.1, \\
\mathrm{E}_{\mathrm{L}}=6.96\end{array}$ & $\begin{array}{l}\mathrm{E}_{\mathrm{L}} / \phi \\
69.6\end{array}$ & 0.03 & 6.0 & $\mathrm{i}$ & $0.3162 \mathrm{i}$ \\
& $\begin{array}{l}E_{L}=G_{L T} \times \\
\left(\varphi+2 v_{L T}+1.0\right)\end{array}$ & & & & & & \\
& $0.1 \leq \phi \leq 4.5$ & & & & & & \\
\hline 3 & Graphite-epoxy & 144.8 & 11.7 & 0.21 & 9.66 & $0.951 \mathrm{i}$ & $3.696 \mathrm{i}$ \\
\hline 4 & Glass-epoxy & 48.26 & 17.24 & 0.29 & 6.89 & $0.685 \mathrm{i}$ & $2.440 \mathrm{i}$ \\
\hline 5 & Graphite-epoxy & 138.9 & 8.96 & 0.3 & 7.1 & $0.925 \mathrm{i}$ & $4.255 \mathrm{i}$ \\
\hline
\end{tabular}

Table 2 Stress intensity factors for the plate with the central crack subject to tension for material No. 1

\begin{tabular}{|l|l|l|}
\hline $\mathrm{a} / \mathrm{w}$ & $\mathrm{K}_{\mathrm{I}} / \mathrm{K}_{0}$ (Present) & $\mathrm{K}_{\mathrm{I}} / \mathrm{K}_{0}$ (Analytical)[28] \\
\hline 0.1 & 1.00 & 1.00 \\
\hline 0.15 & 1.01 & 1.01 \\
\hline 0.2 & 1.01 & 1.02 \\
\hline 0.25 & 1.03 & 1.03 \\
\hline 0.3 & 1.05 & 1.05 \\
\hline 0.35 & 1.07 & 1.07 \\
\hline 0.4 & 1.10 & 1.10 \\
\hline 0.45 & 1.14 & 1.13 \\
\hline 0.5 & 1.19 & 1.17 \\
\hline
\end{tabular}

Table 3 Stress intensity factors for the plate with the central slant crack subject to tension for material No. $3\left(\phi=45^{\circ}\right)$

\begin{tabular}{|r|c|c|c|c|c|c|}
\hline & $\mathrm{K}_{\mathrm{I}} / \mathrm{K}_{0}$ (Present) & $\mathrm{K}_{\mathrm{II}} / \mathrm{K}_{0}$ (Present) & $\mathrm{K}_{\mathrm{I}} / \mathrm{K}_{0}[2]$ & $\mathrm{K}_{\mathrm{II}} / \mathrm{K}_{0}[2]$ & $\mathrm{K}_{\mathrm{I}} / \mathrm{K}_{0}[8]$ & $\mathrm{K}_{\mathrm{II}} / \mathrm{K}_{0}[8]$ \\
\hline 0. & 0.5217 & 0.5082 & 0.5220 & 0.5070 & 0.5100 & 0.5000 \\
\hline 45 & 0.5207 & 0.5147 & 0.5150 & 0.5050 & 0.5120 & 0.5080 \\
\hline 90 & 0.5138 & 0.5089 & 0.5130 & 0.5090 & 0.5250 & 0.5070 \\
\hline 105 & 0.5155 & 0.5101 & 0.5130 & 0.5100 & 0.5270 & 0.5040 \\
\hline 120 & 0.5185 & 0.5127 & 0.5240 & 0.5120 & 0.5250 & 0.5020 \\
\hline
\end{tabular}




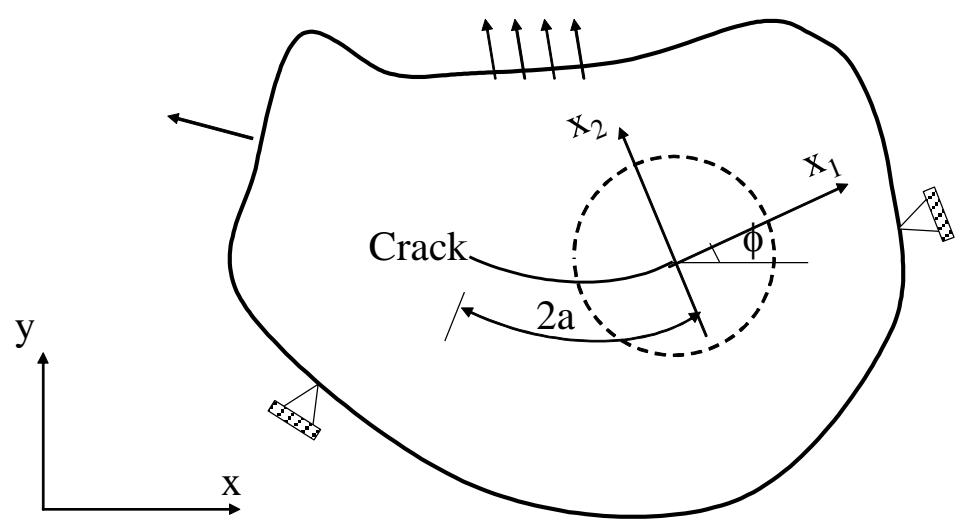

Fig. 1 General crack body under mixed-mode loading

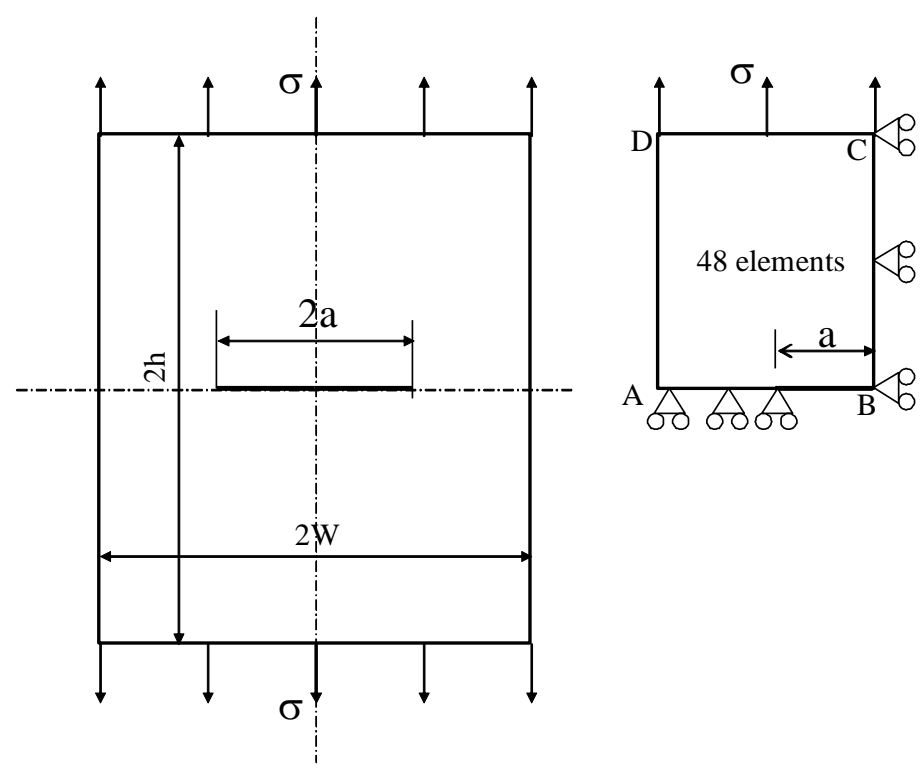

Figure 2 Central crack in a rectangular plate subject to tension 

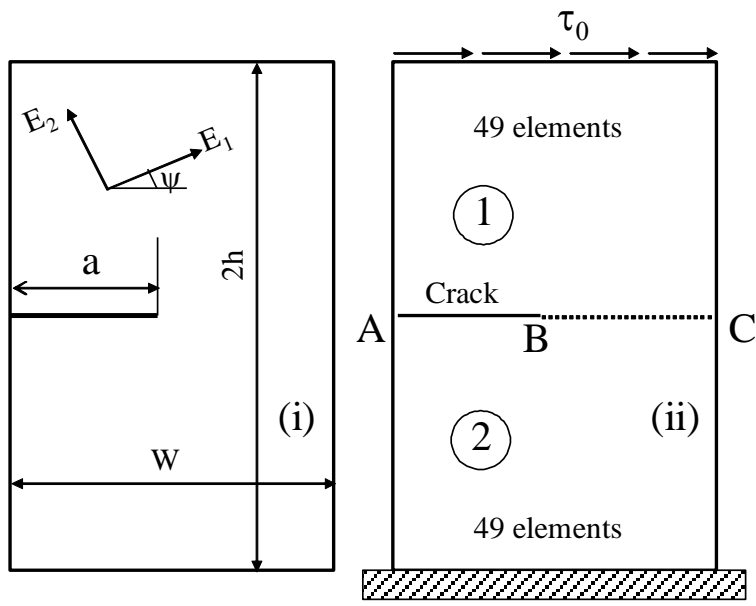

Figure 3 Single edge crack in a cantilever plate loaded by shear stresses at its free end
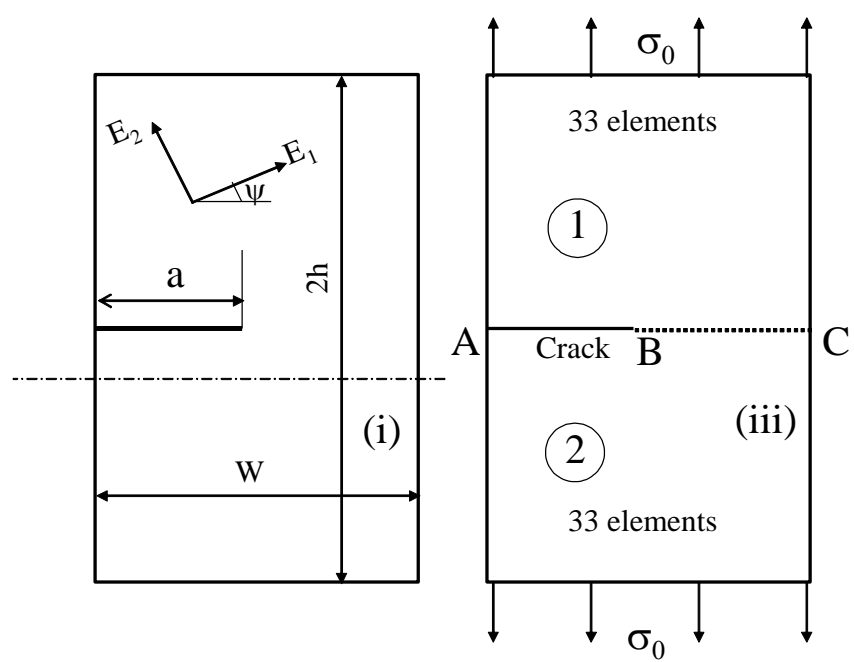

Figure 4 Single edge crack in a rectangular plate subject to tensile stresses at the ends 




Figure 5 Central slant crack in a rectangular plate subject to tension

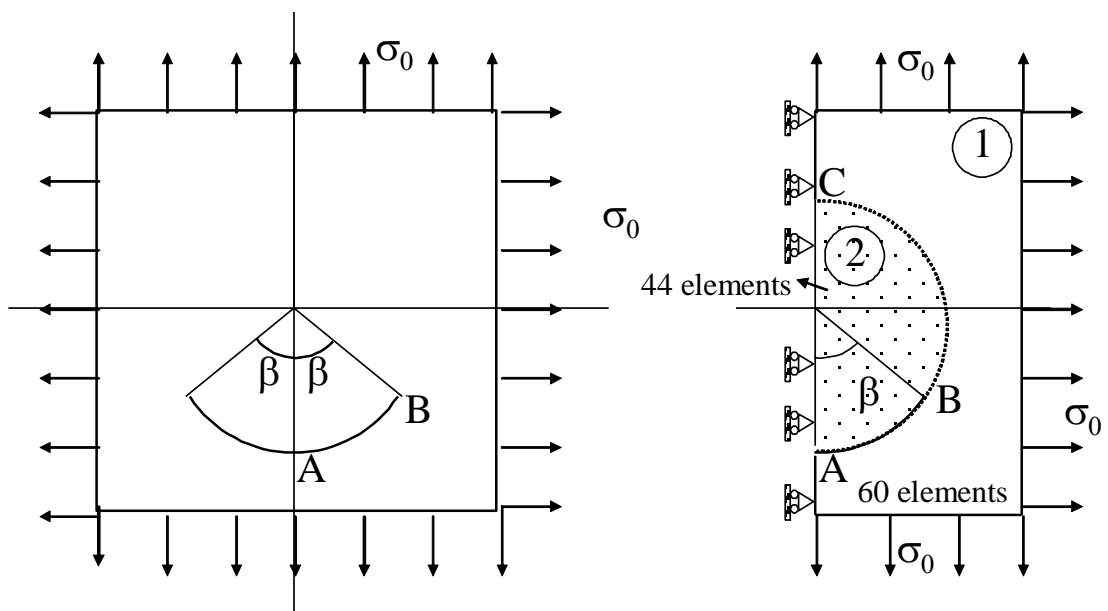

Fig. 6 A circular arc crack in an infinite plate subject to equi-biaxial tension 
Fig. 7 Variation of stain energy release rate with respect to the crack length for the plate with a central crack subject to tension, for material No.1

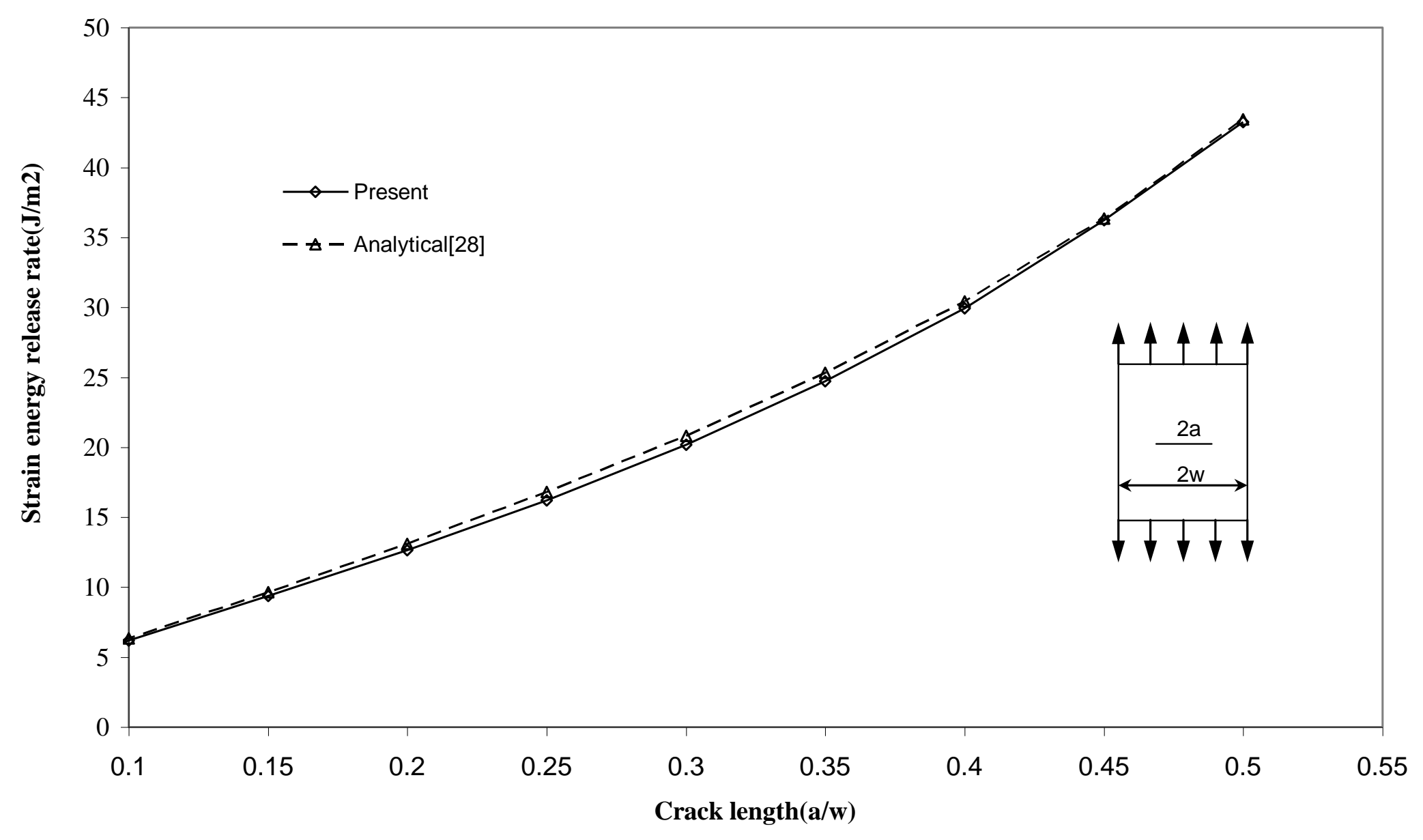


Fig.8 Variation of stress intensity factor $\left(K_{I} / K_{0}\right)$ with respect to the change of $\phi\left(E_{1} / E_{2}\right)$ for the plate with different central crack lengths $(\mathrm{a} / \mathrm{w})$ subject to tenion for material No. 2

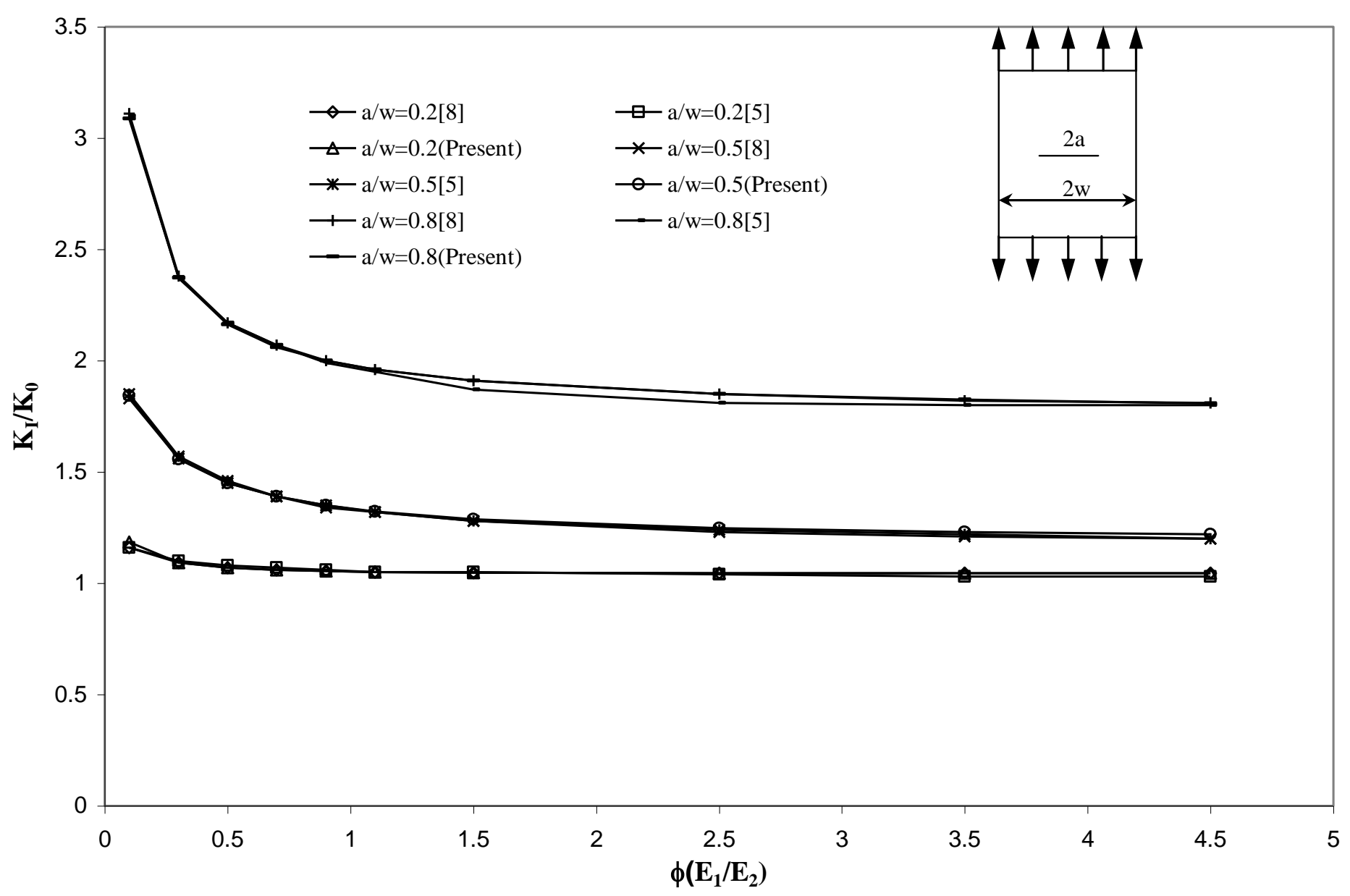









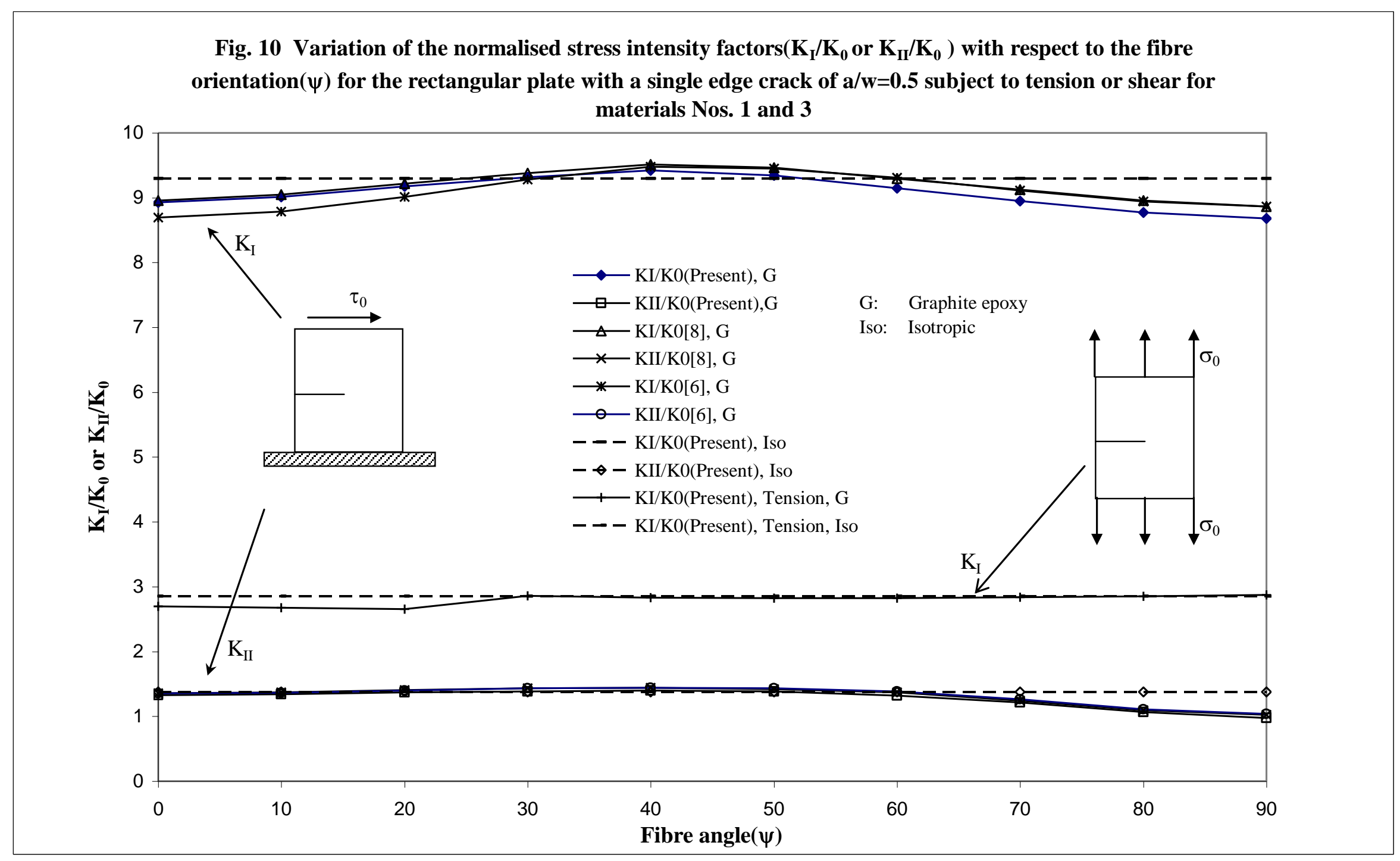


Fig. 11 Variation of strain energy release rate with respect to the fibre orientation $(\psi)$ for the rectangular plate with a single edge crack of $a / w=0.5$ subject to shear for material No. 3

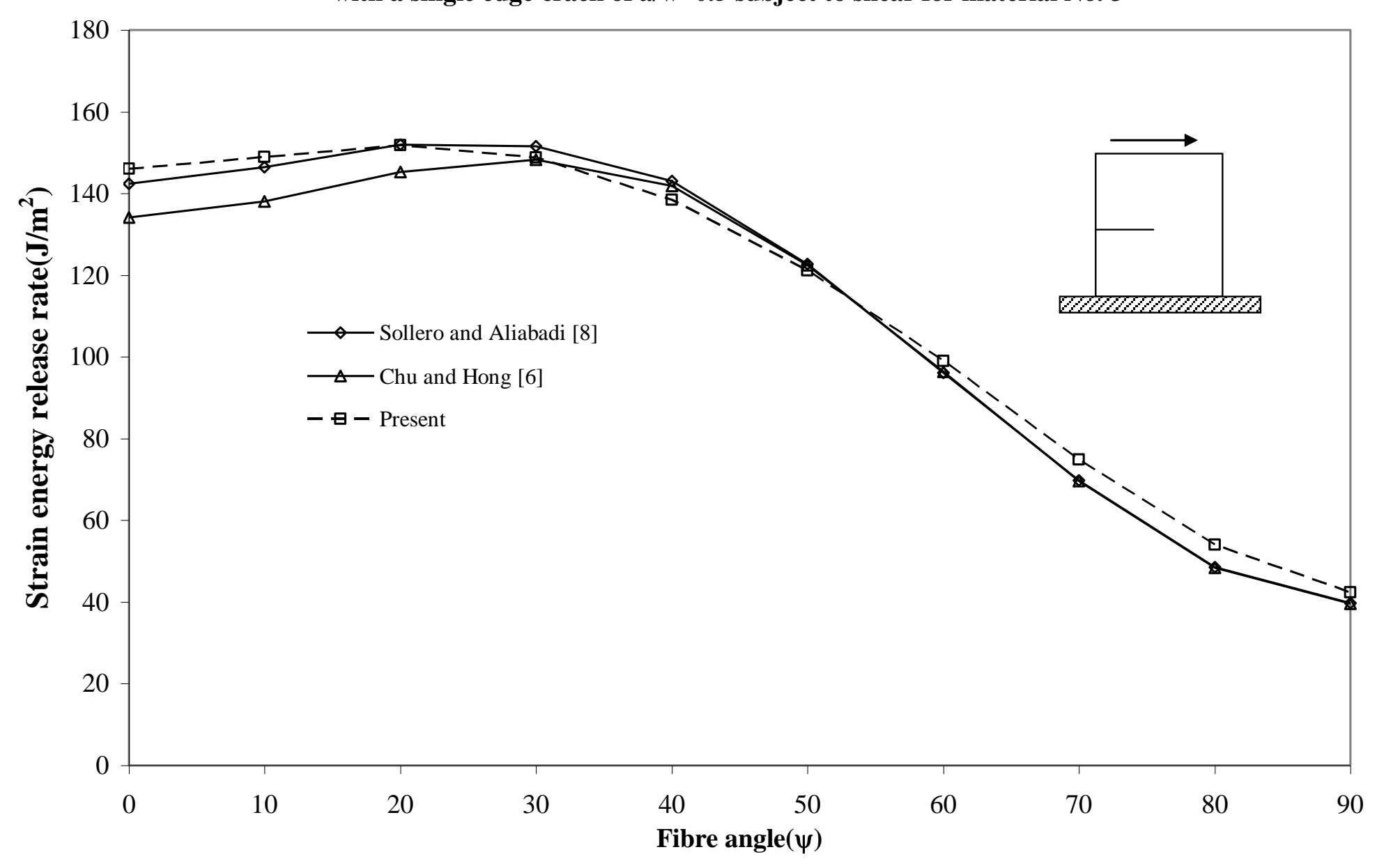









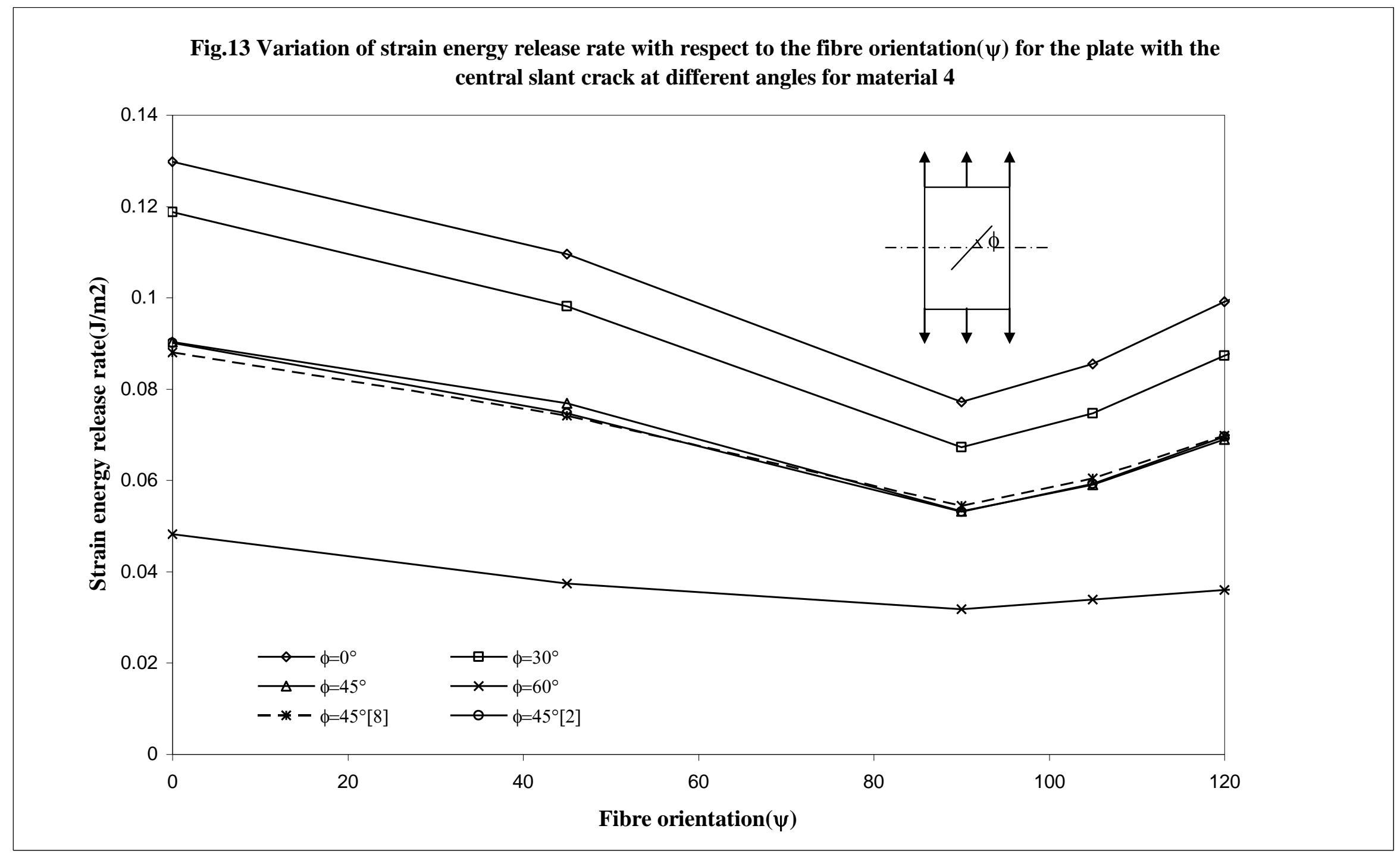




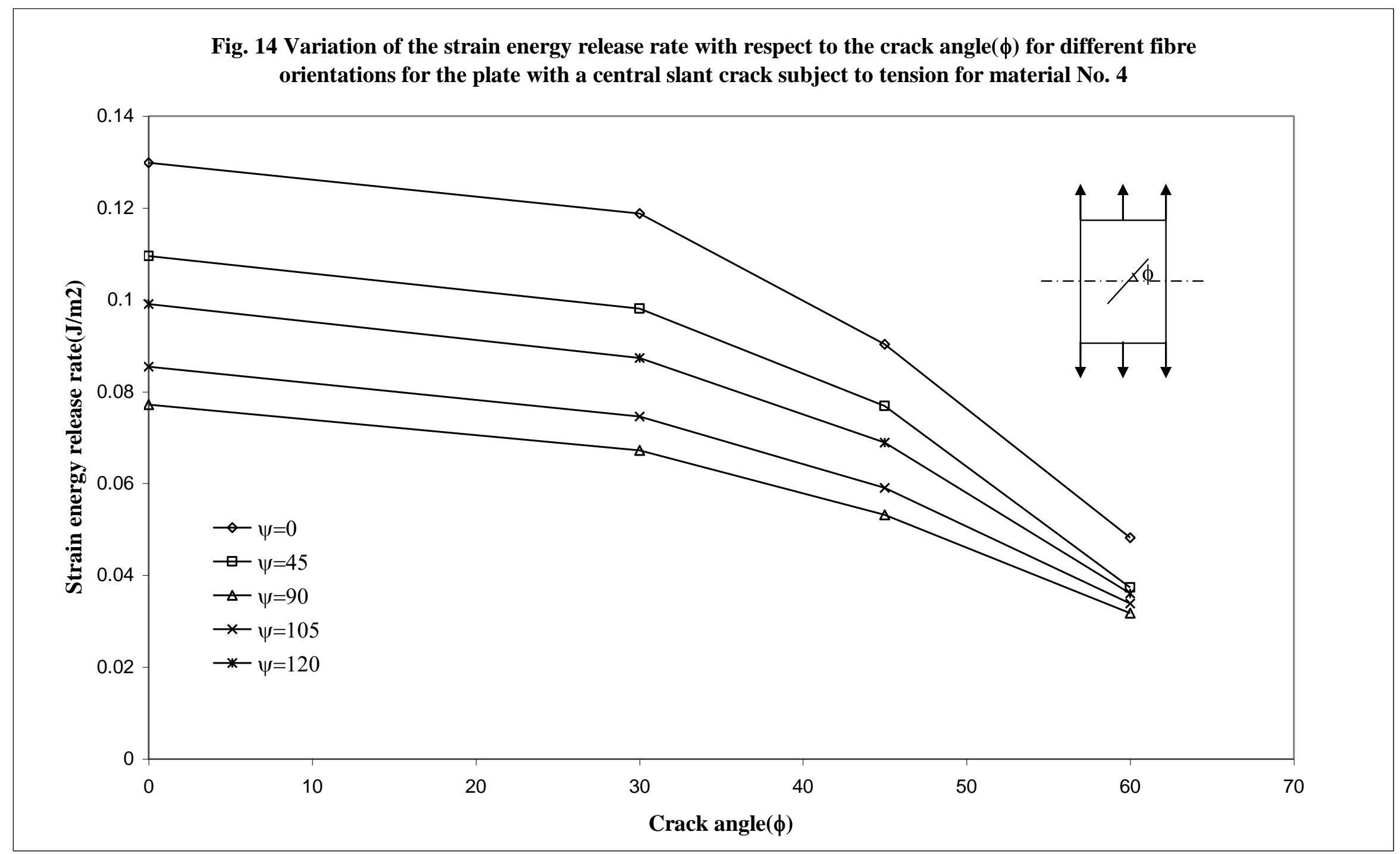




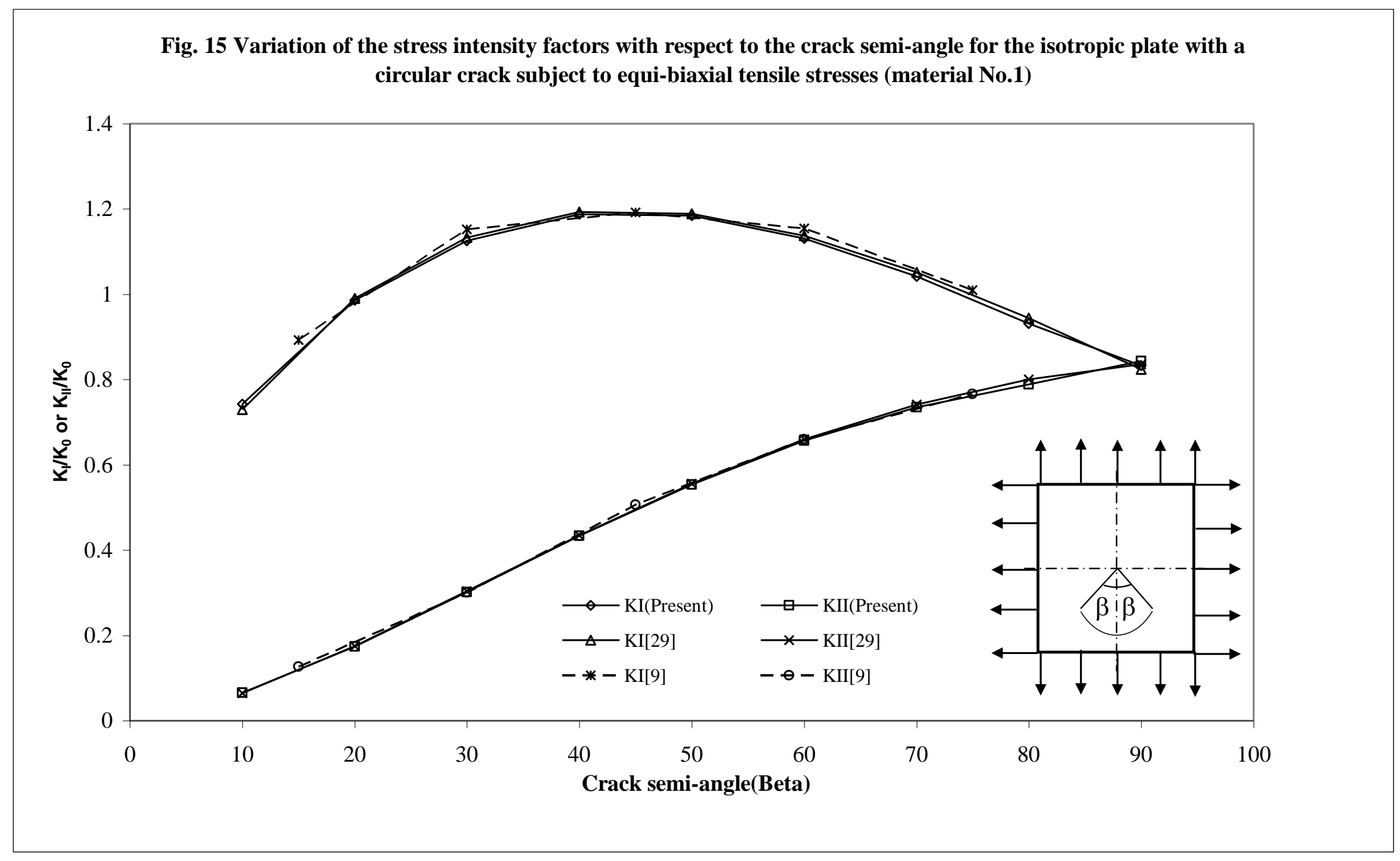


Fig. 16 Variation of the strain energy release rate with respect to the crack semi-angle for the isotropic plate with a circular crack subject to equi-biaxial tensile stresses (material No.1)






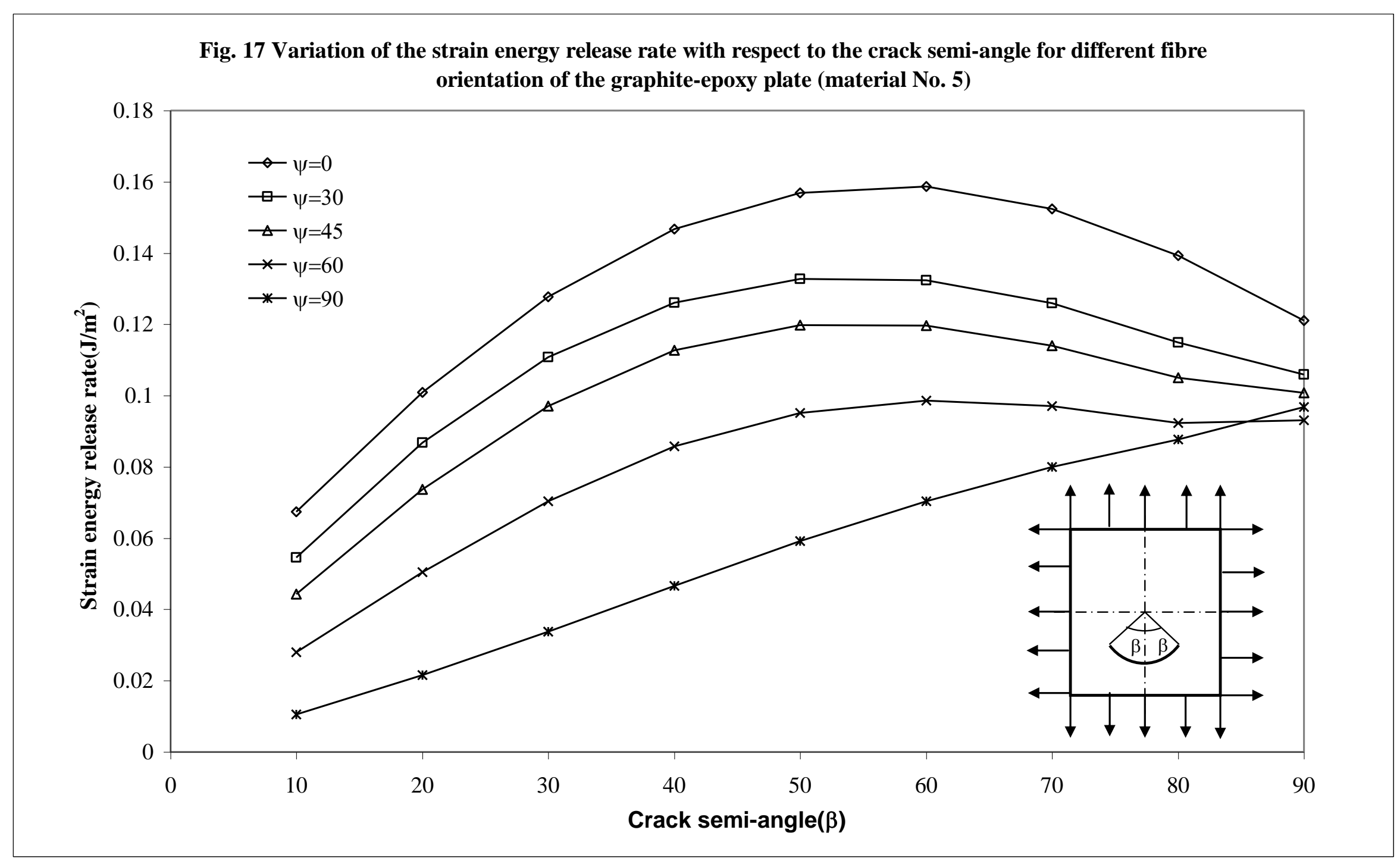


Fig. 18 Variation of the normalized stress intensity factors with respect to the crack semi-angle of a graphiteepoxy plate for the fibre angle of $\psi=90$

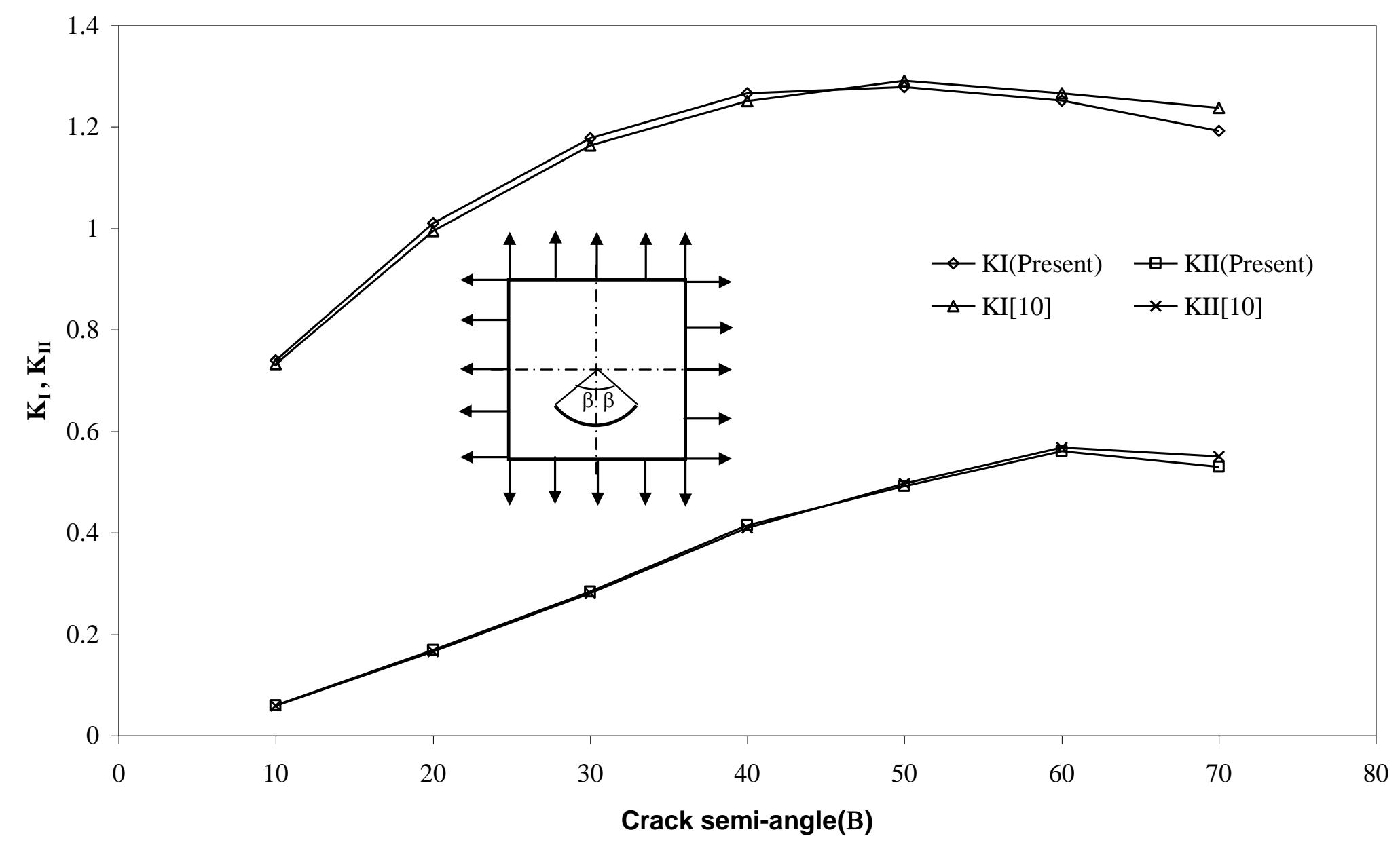

